\title{
Using response time distributions to examine top-down influences on attentional capture
}

\author{
Bryan R. Burnham
}

Published online: 14 November 2012

(C) Psychonomic Society, Inc. 2012

\begin{abstract}
Three experiments examined contingent attentional capture, which is the finding that cuing effects are larger when cues are perceptually similar to a target than when they are dissimilar to the target. This study also analyzed response times (RTs) in terms of the underlying distributions for valid cues and invalid cues. Specifically, an ex-Gaussian analysis and a vincentile analysis examined the influence of top-down attentional control settings on the shift and skew of RT distributions and how the shift and the skew contributed to the cuing effects in the mean RTs. The results showed that cue/ target similarity influenced the size of cuing effects. The RT distribution analyses showed that the cuing effects reflected only a shifting effect, not a skewing effect, in the RT distribution between valid cues and invalid cues. That is, top-down attentional control moderated the cuing effects in the mean RTs through distribution shifting, not distribution skewing. The results support the contingent orienting hypothesis (Folk, Remington, \& Johnston, Journal of Experimental Psychology: Human Perception and Performance, 18, 1030-1044, 1992) over the attentional disengagement account (Theeuwes, Atchley, \& Kramer, 2000) as an explanation for when top-down attentional settings influence the selection of salient stimuli.
\end{abstract}

Keywords Attentional capture - Attentional control ·

Response time distribution

How and when do top-down settings and bottom-up signals moderate the allocation of attention toward salient items? Some propose that salient items receive priority and are selected in a stimulus-driven manner (e.g., Theeuwes, 1992, 1994, 2010; Yantis, 1993, 2000; Yantis \& Egeth, 1999). Others propose that salient items are selected only if they are relevant to current goals (e.g., Folk, Remington, \& Johnston, 1992; Folk,

B. R. Burnham $(\bowtie)$

Department of Psychology, The University of Scranton,

Scranton, PA 18510, USA

e-mail: attention.perform@gmail.com
Remington, \& Wright, 1994). Although top-down modulation of attention is well-established, the issue of how and when this modulation occurs is contested. Part of the issue may be the reliance on measures of central tendency of behavioral responses-namely, mean response times $\left(M_{\mathrm{RT}}\right)$ - to infer when top-down modulation occurs. Results of studies using differences in $M_{\mathrm{RT}}$ (or lack thereof) between conditions do not unambiguously support one side of the debate. This study went beyond using measures of central tendency by examining top-down modulation of the shift and skew of RT distributions in attentional capture tasks. Identifying how top-down control influences RT distributions provided insight as to when top-down control modulates the selection of salient stimuli.

Evidence that salient items are selected only if they are featurally relevant comes from Folk et al. (1992), in which a color cue or onset cue appeared $150 \mathrm{~ms}$ prior to a target that was an onset singleton for some subjects and a color singleton for others. Folk et al. (1992) hypothesized that subjects would enter the target-defining feature into an attentional set that would moderate shifting attention toward the cues. Specifically, cues that shared a feature with the attentional set would capture attention, but cues that did not share a feature with the attentional set would not. Consistent with this contingent orienting hypothesis, only color cues captured attention in the color target group, and only onset cues captured attention in the onset target group. Thus, bottom-up signals interacted with top-down settings so that only salient items that were relevant to the attentional set captured attention. (Hereafter, target relevant refers to cues that match the attentional set, and target irrelevant refers to cues that do not match the attentional set.)

Much research has revealed an interaction between topdown settings and bottom-up signals on the control of attention (e.g., Anderson \& Folk, 2010; Ansorge \& Heumann, 2003; Folk \& Remington, 1998, 2006, 2008; Folk et al., 1992; Folk et al., 1994; Gibson \& Kelsey, 1998; for reviews, see Burnham, 2007; Theeuwes, 2010). But according to the attentional disengagement account, all salient stimuli 
capture attention in a stimulus-driven manner. According to this account, the lack of cuing effects by target-irrelevant cues is due to a disengagement of attention away from the cue in the 150-ms cue-target onset asynchrony (CTOA), and cuing effects by target-relevant cues reflect no disengagement. Thus, the attentional set modulates when attention shifts away from an attention-capturing item, not whether an item captures attention (Belopolsky, Schreij, \& Theeuwes, 2010; Theeuwes, 2010; Theeuwes, Atchley, \& Kramer, 2000). In support of this, Theeuwes et al. found that a color singleton distractor (e.g., a single green item among red items) elevated RTs when it appeared 50 or $100 \mathrm{~ms}$ prior to the onset of a target, but not between 150 and $300 \mathrm{~ms}$ prior to the target (see also Lamy \& Egeth, 2003; Theeuwes \& Godijn, 2002). Thus, attention was captured, but with enough time, attention disengaged from the distractor, thereby nullifying any observable attentional capture effect.

Belopolsky et al. (2010) obtained results consistent with the disengagement account. In their Experiment 4, on each trial, subjects were instructed to choose which one of two targets (red or onset) they wanted to locate. If the target that appeared was congruent with the chosen target, the subjects were to respond (go trial), and they were to withhold their response otherwise (no-go trial). A color cue or onset cue preceded the target by $150 \mathrm{~ms}$, and cues that were target relevant elicited positive cuing effects. However, cues that were target irrelevant elicited negative cuing effects; that is, responses were faster following invalid cues (cue and target in different locations) than following valid cues (cue and target in same location). According to Belopolsky et al., "suppression of the nonmatching cue location suggests that top-down attentional control could not prevent attentional capture by the cue but operated by rapid disengagement of attention from the cued location, followed by suppression of processing at that location" (p. 356). However, negative cuing effects may also reflect the attentional set suppressing attention from being captured, thereby slowing attention from shifting to the cued location (Lamy, Leber, \& Egeth, 2004), consistent with the contingent orienting hypothesis.

Both the contingent orienting hypothesis and the disengagement account predict the same cue/target similarity $x$ cuing effect interaction, with positive cuing effects for target-relevant cues and absent or negative cuing effects for target-irrelevant cues. Hence, results such as Folk et al.'s (1992) and Belopolsky et al.'s (2010) cannot distinguish between the hypotheses. One issue may be the reliance on $M_{\mathrm{RT}}$ and cuing effects in $M_{\mathrm{RT}}$. If one accepts the disengagement account, cuing effects cannot be used to detect that a targetirrelevant cue has captured attention, because the initial capture of attention and following disengagement of attention are subsumed by the same variable $\left(M_{\mathrm{RT}}\right)$, making it difficult to disentangle the two effects. A solution is to estimate the attentional capture effect and disengagement of attention separately and examine their combined influence on cuing effects in $M_{\mathrm{RT}}$. One approach is to analyze RT distributions.

RT data tend to be positively skewed, with $M_{\mathrm{RT}}$ influenced by both the central tendency and skew of the RT distribution. If RTs are normally distributed, $M_{\mathrm{RT}}$ estimates $\mu$, and manipulations that result in a difference in $M_{\mathrm{RT}}$ reflect a shift in $\mu$. But in positively skewed distributions, because skew influences $M_{\mathrm{RT}}$, manipulations resulting in a difference in $M_{\mathrm{RT}}$ may not reflect a change in $\mu$; rather, a manipulation might affect skew and, in turn, affect $M_{\mathrm{RT}}$ (e.g., Andrews \& Heathcote, 2001; Balota \& Yap, 2011; Balota, Yap, Cortese, \& Watson, 2008; Heathcote, Popiel, \& Mewhort, 1991; Luce, 1986; Yap, Balota, Cortese, \& Watson, 2006). Thus, with positively skewed data, it is ambiguous whether a manipulation that results in a difference in $M_{\mathrm{RT}}$ was due to a difference in $\mu$ (distribution shift), a difference in skew, or a difference in both.

The ex-Gaussian function can be fit to positively skewed RTs to examine how manipulations affect the shift and skew of an RT distribution and how differences in the shift and skew contribute to observed differences in $M_{\mathrm{RT}}$ (Heathcote et al., 1991; Hockley, 1984; Luce, 1986; Ratcliff, 1978; Ratcliff \& Murdock, 1976; Van Zandt, 2000). The ex-Gaussian is a convolution of a normal (Gaussian) distribution and exponential distribution, which represents positive skew (Fig. 1). The exGaussian is bound by three parameters: $\mu$, the mean of the normal distribution; $\sigma$, the standard deviation of the normal distribution; and $\tau$, the central tendency of the exponential distribution, which is analogous to skew. Two properties of the ex-Gaussian are especially important. First, as Luce (1986; Van Zandt, 2000) explained, the ex-Gaussian fits positively skewed data quite well and is well-suited for studies analyzing RTs. Second, the sum of the estimates for $\mu$ and $\tau$ is approximately equal to $M_{\mathrm{RT}}$, because the sum of the true values of $\mu$ and $\tau$ is equal to the true mean of the ex-Gaussian (Balota \& Yap, 2011; Heathcote et al., 1991; Luce, 1986; Yap et al., 2006). Importantly, when RTs are positively skewed and fit an ex-Gaussian distribution, $M_{\mathrm{RT}}$ does not estimate $\mu$ in a normal distribution, because $M_{\mathrm{RT}}$ is now assumed to be a convolution of $\mu$ and $\tau$. This is appealing, because estimates of $\mu$ and $\tau$ can be generated and analyzed separately to determine whether a variable that influenced $M_{\mathrm{RT}}$ did so via $\mu$, $\tau$, or both. As Balota and Spieler (1999) stated, "detailed predictions of . . . specific models could not have been tested with estimates of central tendency" (p. 34).

For example, using a Stroop task, Heathcote et al. (1991) found no facilitation effect in $M_{\mathrm{RT}}$ between a congruent condition (RED written in red ink) and neutral condition (XXX written in red ink). After fitting the ex-Gaussian to each subject's data, Heathcote et al. found a facilitation effect in $\mu$ ( $\mu_{\text {Congruent }}<\mu_{\text {Neutral }}$ ) that was counteracted by an interference effect in $\tau$ ( $\left.\tau_{\text {Congruent }}>\tau_{\text {Neutral }}\right)$. That is, the ex-Gaussian analysis revealed how a null effect in $M_{\mathrm{RT}}$ was due to distribution shifting $(\mu)$ and skewing $(\tau)$ exerting opposite influences on $M_{\mathrm{RT}}$. Thus, an ex-Gaussian analysis-and, in 
Fig. 1 A Gaussian distribution (top), with parameters $\mu$ and $\sigma$, and an exponential distribution (middle), with parameter $\tau$, form an ex-Gaussian distribution (bottom), with parameters $\mu, \sigma$, and $\tau$
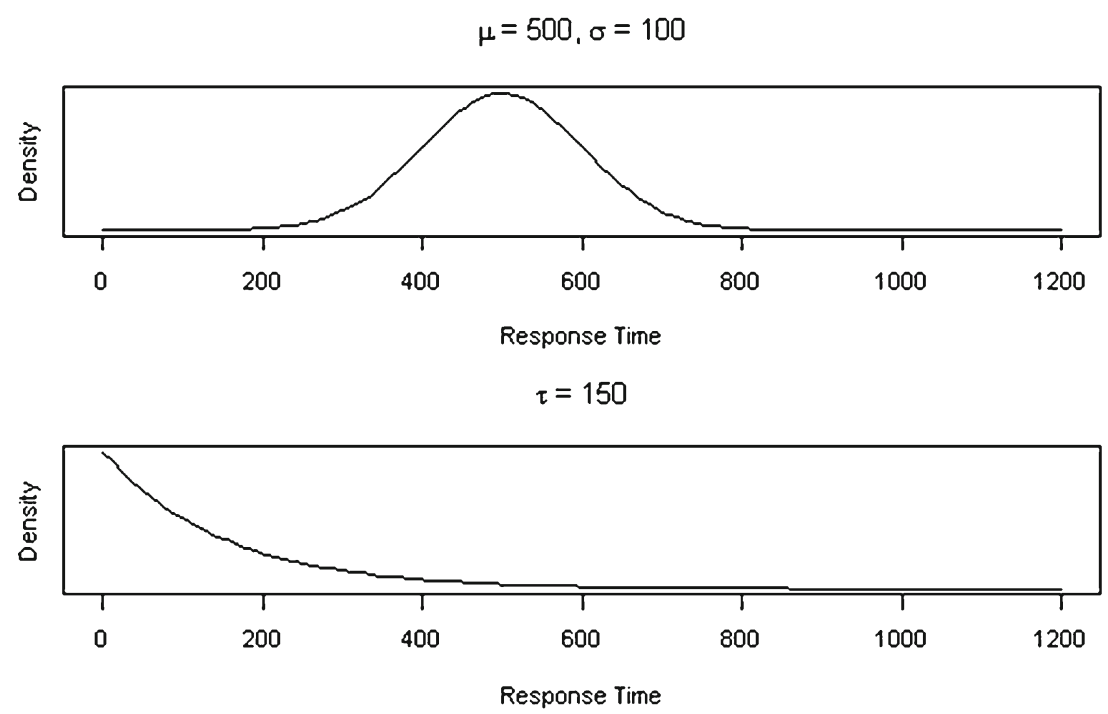

$\mu=500, \sigma=100, \tau=150$

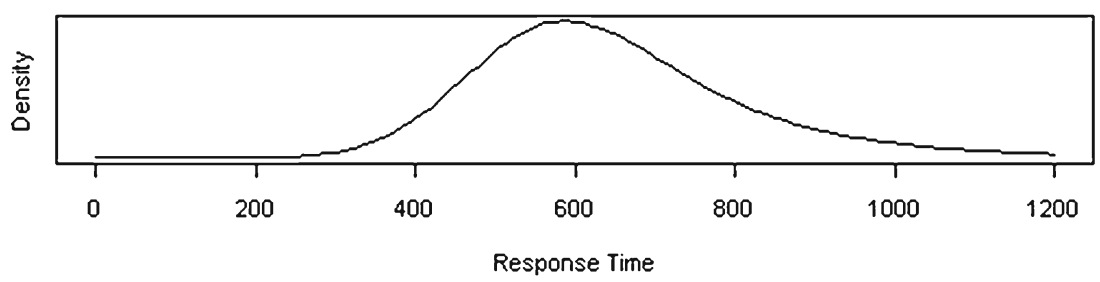

particular, the $\tau$ component - allows one to determine which portion of an RT distribution is affecting $M_{\mathrm{RT}}$.

An influence of the ex-Gaussian parameters $\mu$ and $\tau$ on $M_{\mathrm{RT}}$ may suggest whether different cognitive processes are operating. For example, an influence of $\mu$ on $M_{\mathrm{RT}}$ may reflect stimulus-driven processes, whereas an influence of $\tau$ may reflect top-down processes (Hohle, 1965; Rouder, 2005; Rouder \& Speckman, 2004; Wenger \& Gibson, 2004; but see Luce, 1986; Matzke \& Wagenmakers, 2009). That is, because stimulus-driven processes operate quickly, they may be reflected in shorter RTs corresponding to $\mu$. Thus, manipulations that affect stimulus-driven processing would manifest as differences in $\mu$. Similarly, because top-down-processes operate slowly, they may be reflected in longer RTs corresponding to $\tau$. Hence, manipulations affecting top-down processes would manifest as differences in $\tau$. Although it is speculative to equate specific cognitive processes with specific parameters, results from the word recognition literature suggest that $\mu$ may be sensitive to differences in stimulus-driven processes and that $\tau$ may be sensitive to changes in top-down, attention-demanding processes.

For example, Balota and Spieler (1999) examined the influence of word frequency on lexical decision times (LDTs). A word frequency effect was observed in $M_{\mathrm{RT}}$, where responding was faster to high-frequency words than to low-frequency words, an effect that was influenced by both $\mu$ and $\tau$. Specifically, $\mu$ was smaller for high-frequency words, and $\tau$ was larger for low-frequency words. Faster responding to high-frequency words may reflect stimulus-driven encoding; hence, the difference in $\mu$ suggests that $\mu$ is sensitive to stimulus-driven processing. Slower responding to low-frequency words may reflect a strategic memory search; hence, the difference in $\tau$ suggests that $\tau$ is sensitive to changes in top-down processes.

Similarly, Balota et al. (2008) examined the influence of $\mu$ and $\tau$ on semantic priming, which is the finding that LDTs are shorter on target words (cat) following related primes (DOG) than following unrelated primes (WALL). The semantic priming effect in $M_{\mathrm{RT}}$ was influenced only by $\mu$. Given that semantic priming may reflect a stimulus-driven preactivation mechanism (Neely, 1977), this suggests that $\mu$ may be sensitive to stimulus-driven processing. Importantly, Balota et al. also observed an increase in semantic priming when the target was perceptually degraded, which suggests that subjects relied more on the prime to assist processing the target. This increase in the semantic priming effect was isolated to $\tau$, suggesting that $\tau$ may be sensitive to changes in top-down processes. In short, evidence suggests that $\mu$ and $\tau$ are sensitive to changes in stimulus-driven and top-down processing, respectively, although $\mu$ and $\tau$ may not directly measure those processes.

Because involuntary shifts of attention toward salient stimuli (attentional capture) reflect perceptual process, cuing effects may reflect an RT distribution shift between valid and invalid cue conditions $\left(\mu_{\text {Valid }}<\mu_{\text {Invalid }}\right)$. That is, if attention shifts toward a cue, this should facilitate 
responding to targets at that location, and the RT distribution for valid cues should be shifted to the left of the distribution for invalid cues. The question is how top-down modulation might influence the shift and skew of the RT distributions.

The contingent orienting hypothesis and disengagement account assume that top-down attentional settings moderate the capture of attention but differ with respect to when this occurs (before or after capture)-hence, how top-down modulation might influence the shift and skew of RT distributions (Fig. 2). According to the contingent orienting hypothesis, top-down modulation occurs prior to capture. Target-relevant cues should elicit a cuing effect and RT distribution shift $\left(\mu_{\text {Valid }}<\mu_{\text {Invalid }}\right)$, but target-irrelevant cues should elicit no cuing effect and no shift $\left(\mu_{\text {Valid }}=\mu_{\text {Invalid }}\right)$. The hypothesis predicts no influence of $\tau\left(\tau_{\text {Invalid }}=\tau_{\text {Valid }}\right)$, because top-down control that may be associated with $\tau$ exerts an influence prior to attention being captured; that is, top-down control is engaged a priori to cue onset. The hypothesis predicts a cue/target similarity $\times$ cuing effect interaction for $\mu$, but not for $\tau$. In contrast, the disengagement account assumes that top-down modulation occurs after stimulus-driven capture by a salient cue. Both targetrelevant and target-irrelevant cues should elicit a cuing effect and distribution shift $\left(\mu_{\text {Valid }}<\mu_{\text {Invalid }}\right)$. Critically, because disengagement is assumed to occur after attention is captured - that is, top-down control is engaged a posteriori to cue onset - disengagement may influence larger RTs that may be associated with $\tau$. As such, the lack of cuing effects in $M_{\mathrm{RT}}$ for target-irrelevant cues may reflect a skew effect $\left(\tau_{\text {Valid }}>\tau_{\text {Invalid }}\right)$ that counteracts the shift effect, with the result being no observable cuing effect: $\left(\mu_{\text {Invalid }}-\mu_{\text {Valid }}\right)+\left(\tau_{\text {Invalid }}-\tau_{\text {Valid }}\right)=$ $M_{\text {Invalid }}-M_{\text {Valid }}=0 \mathrm{~ms}$. There should be no influence of $\tau$ target-relevant cues $\left(\tau_{\text {Valid }}=\tau_{\text {Invalid }}\right)$, because disengagement should not occur. Thus, the account predicts a cue/target similarity $\times$ cuing effect interaction for $\tau$, but not for $\mu$.

In short, the ex-Gaussian analysis allows predictions to be contrasted between the contingent orienting hypothesis and disengagement account. No study examining top-down modulation of attentional capture has used an ex-Gaussian analysis, ${ }^{1}$ but several studies have used vincentized analyses

\footnotetext{
${ }^{1}$ Wenger and Gibson (2004) used hazard functions to examine changes in processing capacity as a function of cue-target similarity in a contingent capture task-specifically, whether the ordering of hazard functions fit to data from valid and invalid cue conditions differed with respect to cue-target similarity. Their results were consistent with the contingent orienting hypothesis (Folk et al., 1992), that processing capacity differs on the basis of similarity between the cue and target. Wegner and Gibson also failed to find partial orderings of hazard functions in a target-irrelevant (incongruent) condition, which could be taken as evidence against disengagement. As was explained by Wenger and Gibson, a benefit of this approach is that fitting hazard functions does not require an assumption that data follow a parametric distribution, as is the case with fitting the ex-Gaussian.
}

(Ansorge \& Horstmann, 2007; Ansorge, Horstmann, \& Carbone, 2005). In a vincentized analysis, each subject's data are separated into conditions and are rankordered. Data are placed into bins called quantiles, with each representing a percentage of data. The $M_{\mathrm{RT}}$ within a quantile is averaged across subjects, and differences between conditions as a function of quantile are examined. For example, Ansorge et al. found that target-relevant (better-marching) distractors elicited capture effects earlier in an RT distribution than did target-irrelevant (less-marching) distractors, consistent with the contingent orienting hypothesis.

Quantile plots are used in conjunction with exGaussian analyses because $\mu$ and $\tau$ have specific influences on their shape. Generally, if a difference in $M_{\mathrm{RT}}$ is due to $\mu$, the difference between conditions will not change across quantiles, but if a difference in $M_{\mathrm{RT}}$ is due to $\tau$, the difference will change across quantiles (see Fig. 2 in Balota \& Yap, 2011). The contingent orienting hypothesis predicts a difference between valid and invalid conditions that does not vary across quantile for targetrelevant cues and no difference between valid and invalid conditions for target-irrelevant cues. In contrast, the disengagement account predicts that the difference between valid and invalid cues should decrease across quantiles for target-irrelevant cues and that the difference will not vary across quantiles for target-relevant cues.

In the following three experiments, cuing effects were analyzed using $M_{\mathrm{RT}}$ and also with an ex-Gaussian analysis to test the predictions from the contingent orienting hypothesis and the disengagement account. The experiments were similar to those in Folk et al. (1992), and cuing effects were predicted, and observed, to be modulated by top-down settings. The question addressed was how top-down modulation would influence the parameters $\mu$ and $\tau$ and how these parameters would contribute to the top-down modulation of cuing effects in $M_{\mathrm{RT}}$.

\section{General method}

\section{Subjects}

University of Scranton undergraduates participated for credit toward a research requirement. Forty-one subjects (23 female, 36 right-handed) completed Experiment 1; 32 subjects (17 female, 26 right-handed) completed Experiment 2; and 27 subjects ( 19 female, 25 right-handed) completed Experiment 3. Subjects ranged from 18 to 25 years old $(M=18.96, S D=1.05)$ and all reported normal or corrected-to-normal vision. The task required $45 \mathrm{~min}$, and each subject also completed an unrelated working memory task. 
Contingent Orienting Hypothesis Predictions

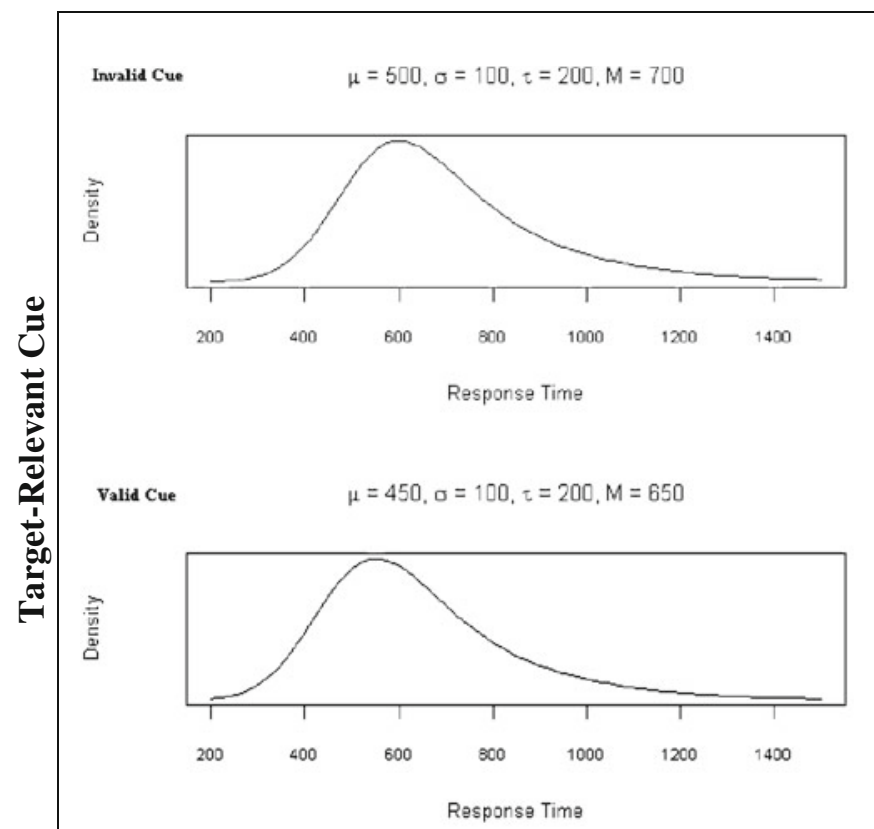

Cuing Effects: $\mu=50 \mathrm{~ms} ; \tau=0 \mathrm{~ms} ; M=50 \mathrm{~ms}$

Invalid Cue $\quad \mu=500, \sigma=100, \tau=200, M=700$

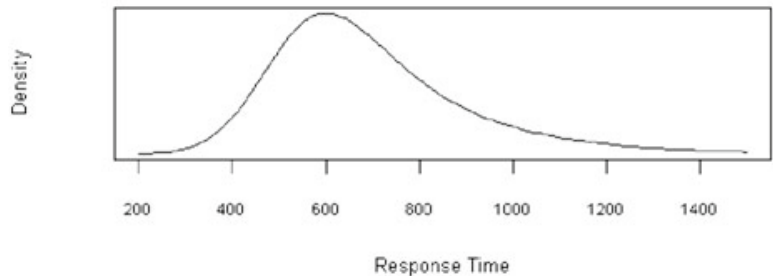

Cuing Effects: $\mu=0 \mathrm{~ms} ; \tau=0 \mathrm{~ms} ; M=0 \mathrm{~ms}$
Attentional Disengagement Predictions

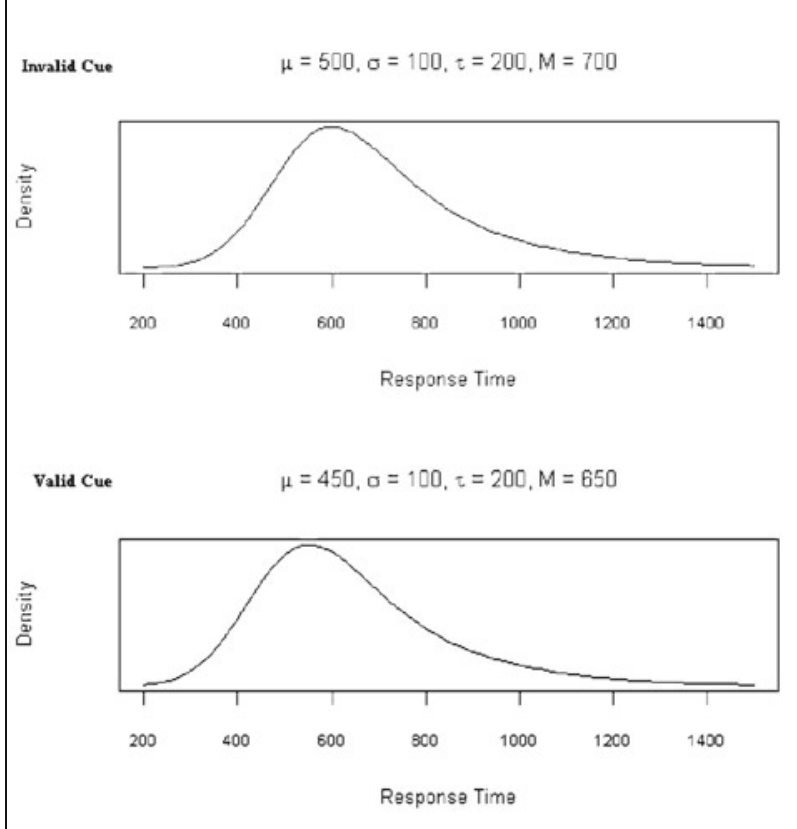

Cuing Effects: $\mu=50 \mathrm{~ms} ; \tau=0 \mathrm{~ms} ; M=50 \mathrm{~ms}$

Invalid Cue $\quad \mu=500, \sigma=100, \tau=200, M=700$

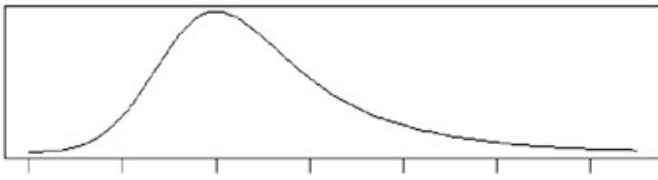

$\begin{array}{lllllll}200 & 400 & 600 & 800 & 1000 & 1200 & 1400\end{array}$

Response Time

Valid Cue $\quad \mu=450, \sigma=100, \tau=250, M=700$

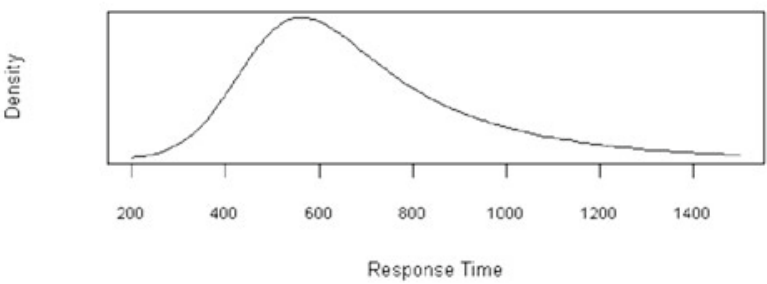

Cuing Effects: $\mu=50 \mathrm{~ms} ; \tau=-50 \mathrm{~ms} ; M=0 \mathrm{~ms}$

Fig. 2 Predicted effects on the ex-Gaussian parameters $\mu$ and $\tau$ and on $M_{\mathrm{RT}}$ for validly and invalidly cued target-relevant and target-irrelevant cues

Design

Each experiment included the within-subjects factors cue validity (valid vs. invalid) and cue type. Experiment 1 included the between-subjects factor target type (onset vs. color).
Apparatus

Each experiment was programmed and presented with E-Prime v2.0.8.22 software (Psychology Software Tools Inc.) on a Dell 755 computer with a Pentium Core 2 Duo processor $(2.33 \mathrm{GHz})$ connected to a Dell E178Fpv monitor $(60 \mathrm{~Hz})$. 
Subjects were tested individually and sat $60 \mathrm{~cm}$ from the monitor, which was height adjusted. A five-button response box was used for responding, and an OptiCAL RS-232 photometer measured luminance.

Stimuli

In each experiment, the stimuli appeared in a sequence of frames (Fig. 3). In all frames except for the cue display, five gray placeholders (CIExy, .314, .329; luminance, $20.98 \mathrm{~cd} / \mathrm{m}^{2}$ ) appeared on a black background $\left(0,0 ; 0.16 \mathrm{~cd} / \mathrm{m}^{2}\right)$. The placeholders were $1.53^{\circ} \times 1.53^{\circ}$ with a 2-pixel border. One was centered and contained a gray fixation cross, and the other four were positioned $45^{\circ}, 135^{\circ}, 225^{\circ}$, and $315^{\circ}$ relative to the twelveo-clock position and designated the potential cue and target locations. The distance between the center of the central placeholder and the center of each peripheral placeholder was $4.31^{\circ}$.

On each trial, one of two different cue displays was presented. In onset cue displays, a $1.72^{\circ} \times 1.72^{\circ}$ white box $\left(.314, .329 ; 25.77 \mathrm{~cd} / \mathrm{m}^{2}\right)$ was onset over one peripheral placeholder. In color cue displays, a $1.72^{\circ} \times 1.72^{\circ}$ box was presented over each placeholder. The box at the central placeholder and three peripheral placeholders were green $\left(.314, .537 ; 13.74 \mathrm{~cd} / \mathrm{m}^{2}\right)$, and the box at the fourth peripheral placeholder was a color singleton. Target displays are described in the Method section for each experiment.

\section{Procedure}

Subjects were informed that they would see a series of displays and that their task was to identity a target with a prespecified feature. Subjects were encouraged to respond quickly but to refrain from making errors by pressing a key on the response box with their left or right index finger (key assignment was counterbalanced). Subjects completed 32 practice trials that did not include a cue display and 64 practice trials in which a cue was presented $150 \mathrm{~ms}$ prior to the target. For this second set of practice trials, the different cue types appeared equally often, but randomly, at each of the four peripheral placeholder locations. On these trials and the data collection trials, the target location was independent of the cue location (cue and target coincided $25 \%$ of the time). A total of 768 trials followed, and subjects were given self-paced breaks every 64 trials.

On each data collection trial, the fixation display was presented for $1,000 \mathrm{~ms}$. The cross was erased for a randomly chosen duration of 400-900 ms (increments of $100 \mathrm{~ms}$ ), which was a warning that the trial had started. A cue display was presented for $50 \mathrm{~ms}$, with the type and location of the cue chosen randomly on each trial. After a randomly chosen CTOA, the target display was presented. In Experiment 1, CTOA ranged from 50 to $300 \mathrm{~ms}(25-\mathrm{ms}$ increments). In Experiments 2 and 3, CTOA ranged from 50 to $200 \mathrm{~ms}$ (50-ms increments). If the response was incorrect or if no response was made within $2,000 \mathrm{~ms}$, a $500-\mathrm{Hz}$ tone was played for $500 \mathrm{~ms}$. The next trial began after 1,000 ms.

\section{Experiment 1}

These data were originally published in a study that examined the relationship between working memory and contingent orienting (Burnham, Harris, \& Suda, 2011) and are included here because the methodology and stimuli are similar to those in Folk et al. (1992). Subjects were randomly assigned to identify a red target or an onset target, and in each group, a color cue or onset cue preceded the target. It was expected that subjects would enter the target-defining feature into an attentional set that would modulate the cuing effects. The question was whether the observed interaction between target type, cue type, and cue validity in $M_{\mathrm{RT}}$ would reflect an influence of $\mu$, $\tau$, or both.
Fig. 3 Example trial sequence. In the cue display, the onset cue (top) is the large white placeholder, and the color cue (bottom) is the outlined placeholder among the gray placeholders, which were green in the experiments. Target displays are described in the Method sections

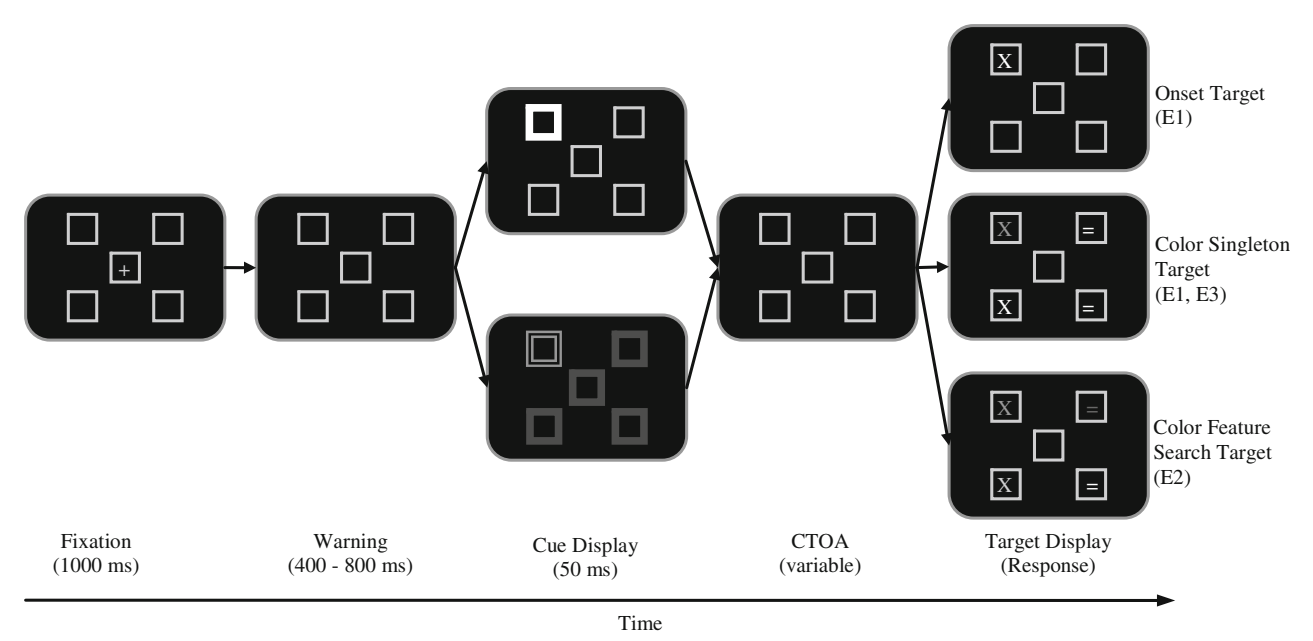


Method

Design

The design was a 2 (target type: onset vs. color) $\times 2$ (cue type: color cue vs. onset cue) $\times 2$ (cue validity: valid vs. invalid) mixed factorial with target type a between-subjects factor and all other factors randomized within blocks. Subjects were randomly assigned to an onset target group $(n=20)$ or a color target group $(n=21)$.

\section{Stimuli}

The cue display contained an onset cue or color cue. For color cues, one box at a peripheral placeholder was red $\left(.447, .334 ; 12.91 \mathrm{~cd} / \mathrm{m}^{2}\right)$, and the box at each other placeholder was green $\left(.314, .537 ; 13.74 \mathrm{~cd} / \mathrm{m}^{2}\right)$.

For subjects in the onset target group, the target was the single gray $\mathrm{X}$ or $=\left(24\right.$-point Sans Serif font, $\left.0.5^{\circ} \times 0.5^{\circ}\right)$ that appeared at a randomly chosen one of the four peripheral locations. For subjects in the color target group, the target was the single red item $\mathrm{X}$ or $=$ that appeared with three gray items. The target appeared in a randomly chosen one of the four peripheral locations, and a gray $\mathrm{X}$ and = appeared in each of the other peripheral locations, with the condition that two Xs and two $=\mathrm{s}$ appeared in every target display.

\section{Results}

Three analyses were performed. First, $M_{\mathrm{RT}}$ and errors were submitted to analyses of variance (ANOVAs) to determine whether contingent capture occurred. Second, analyses were carried out with the parameter estimates $(\mu$, $\sigma, \tau)$ that were obtained after fitting an ex-Gaussian function to each subject's data. Finally, vincentile analyses were performed with $R T$ bin (quantile) included as a factor. For the vincentile analyses, the GreenhouseGeisser correction was used when sphericity was violated. For each experiment, error trials and trials with RTs shorter than $150 \mathrm{~ms}$ were excluded. Of the remaining trials, RTs three standard deviations above or below each subject's overall mean were removed. Trimming resulted in the removal of $4.2 \%$ of the trials $(2.5 \%$ due to error). Trimmed data were used in each analysis, and the patterns did not change in the untrimmed data.

\section{$R T$ and error analyses}

Each subject's $M_{\mathrm{RT}}$ was computed for each cell in the cue type $\times$ cue validity design for each target group. Arithmetic means for each cell appear in Table 1. Results of a 2 (target: color vs. onset) $\times 2$ (cue type: color vs. onset) $\times 2$ (cue validity: valid vs. invalid) ANOVA with repeated measures on the factors cue type and cue validity are presented in Table 2. The main effect of cue validity was significant, reflecting faster responding following valid cues. A main effect of target type was due to faster responses to onset targets. The cue type main effect was nearly significant, as was the target type $\times$ cue type interaction. Importantly, the three-way interaction was significant. No other effect from the omnibus ANOVA was significant, $F \mathrm{~s}<1$. The three-way interaction was examined with separate 2 (cue type) $\times 2$ (cue validity) ANOVAs on the onset target group and color target group. In the color target group, the cue type $\times$ cue validity interaction was significant, reflecting a larger cuing effect by color cues than by onset cues (Table 1). The interaction was also significant in the onset target group, reflecting a larger cuing effect for onset cues than for color cues. Thus, the results show contingent capture.

A 2 (target type) $\times 2$ (cue type) $\times 2$ (cue validity) ANOVA on the errors yielded a significant interaction between target type and cue validity and between cue type and cue validity. The three-way interaction was also significant. No other effects were significant. The three-way interaction reflected a significant cue type $\times$ cue validity interaction in the color target group, but not in the onset target group.

\section{Ex-Gaussian analysis}

Kolmogorov-Smirnov tests on the aggregate distributions were significantly different from normal in each condition, and average chi-square goodness-of-fit statistics showed that the RT distributions did not significantly deviate from the theoretical ex-Gaussian (Table 3). Figure 7 in the Appendix shows an ex-Gaussian function overlaid on the data from all subjects in each target type $\times$ cue type $\times$ cue validity combination. Each bar represents $5 \%$ of the data. As can be seen in Fig. 7, the ex-Gaussian function fits the data very well.

Each subject's data in each cell of the cue type $\times$ cue validity design was fit to an ex-Gaussian function using RTSYS (Heathcote, 1996), which uses continuous maximum likelihood estimation to obtain ex-Gaussian parameters. All fits converged within 500 iterations. Table 3 lists the average number of trials used per subject for parameter estimation. Parameter estimates were averaged across subjects and appear in Table 1, and each subject's parameter estimates for $\mu, \sigma$, and $\tau$ were entered into separate 2 (target type) $\times 2$ (cue type) $\times 2$ (cue validity) ANOVAs. Results of the omnibus ANOVAs with follow up analyses are presented in Table 4.

For $\mu$, each main effect was significant, as were the twoway interactions with target type. Most important, the threeway interaction was significant, which was examined with separate 2 (cue type) $\times 2$ (cue validity) ANOVAs for the onset target group and the color target group. In the color target group, the cue type $\times$ cue validity interaction was 
Table 1 Mean response times (in milliseconds), response accuracy (percentages of errors), and ex-Gaussian parameter estimates $(\mu, \sigma, \tau)$ as a function of cue validity and cue type in Experiments $1-3$ and results of $t$-tests on individual cuing effects with $p$-values and Cohen's $d_{z}$

\begin{tabular}{|c|c|c|c|c|c|c|c|c|}
\hline Experiment & Target type & Cue type & Cue validity & $M_{\mathrm{RT}}$ & $\%$ error & $\mu$ & $\sigma$ & $\tau$ \\
\hline \multirow[t]{24}{*}{ E1 } & \multirow[t]{12}{*}{ Color target } & \multirow[t]{6}{*}{ Color } & Invalid & 571 & 3.3 & 483 & 57 & 89 \\
\hline & & & Valid & 535 & 1.8 & 432 & 45 & 105 \\
\hline & & & Difference & 36 & 1.5 & 51 & 12 & -16 \\
\hline & & & $t$ & 7.91 & 3.82 & 11.22 & 4.31 & 2.91 \\
\hline & & & $p$ & $<.001$ & .001 & $<.001$ & $<.000$ & .009 \\
\hline & & & $d_{\mathrm{z}}$ & 1.72 & 0.83 & 2.49 & 0.95 & 0.63 \\
\hline & & \multirow[t]{6}{*}{ Onset } & Invalid & 558 & 2.4 & 464 & 51 & 97 \\
\hline & & & Valid & 547 & 3.2 & 451 & 52 & 94 \\
\hline & & & Difference & 11 & -0.8 & 13 & -1 & 3 \\
\hline & & & $t$ & 3.09 & 1.78 & 3.55 & 0.47 & 0.58 \\
\hline & & & $p$ & .006 & .090 & .002 & .646 & .570 \\
\hline & & & $d_{\mathrm{z}}$ & 0.68 & 0.39 & 0.77 & 0.10 & 0.13 \\
\hline & \multirow[t]{12}{*}{ Onset target } & \multirow[t]{6}{*}{ Color } & Invalid & 490 & 2.2 & 406 & 50 & 84 \\
\hline & & & Valid & 479 & 2.3 & 401 & 51 & 80 \\
\hline & & & Difference & 12 & -0.2 & 5 & -1 & 4 \\
\hline & & & $t$ & 4.20 & 0.54 & 1.33 & 0.40 & 0.79 \\
\hline & & & $p$ & $<.001$ & .593 & .199 & .692 & .437 \\
\hline & & & $d_{\mathrm{z}}$ & 0.94 & 0.12 & 0.30 & 0.09 & 0.18 \\
\hline & & \multirow[t]{6}{*}{ Onset } & Invalid & 493 & 2.2 & 407 & 48 & 85 \\
\hline & & & Valid & 462 & 2.7 & 380 & 49 & 83 \\
\hline & & & Difference & 31 & -0.5 & 27 & -2 & 3 \\
\hline & & & $t$ & 5.71 & 1.76 & 5.40 & 0.51 & 0.52 \\
\hline & & & $p$ & $<.001$ & .095 & $<.001$ & .614 & .612 \\
\hline & & & $d_{\mathrm{z}}$ & 1.28 & 0.39 & 1.21 & 0.11 & 0.12 \\
\hline \multirow[t]{18}{*}{ E2 } & \multirow[t]{18}{*}{ Color target } & \multirow[t]{6}{*}{ Same color } & Invalid & 640 & 3.5 & 521 & 63 & 118 \\
\hline & & & Valid & 593 & 3.8 & 470 & 52 & 122 \\
\hline & & & Difference & 47 & -0.3 & 51 & 11 & -3 \\
\hline & & & $t$ & 8.58 & 0.42 & 11.66 & 3.40 & 0.70 \\
\hline & & & $p$ & $<.001$ & .681 & $<.001$ & .002 & .493 \\
\hline & & & $d_{\mathrm{z}}$ & 1.57 & 0.08 & 2.13 & 0.62 & 0.13 \\
\hline & & \multirow[t]{6}{*}{ Different color } & Invalid & 623 & 3.7 & 502 & 60 & 120 \\
\hline & & & Valid & 617 & 3.1 & 497 & 51 & 121 \\
\hline & & & Difference & 5 & 0.6 & 5 & 8 & 0 \\
\hline & & & $t$ & 1.26 & 1.59 & 1.08 & 2.49 & 0.10 \\
\hline & & & $p$ & .216 & .122 & .288 & .019 & .924 \\
\hline & & & $d_{\mathrm{z}}$ & 0.23 & 0.29 & 0.20 & 0.45 & 0.02 \\
\hline & & \multirow[t]{6}{*}{ Onset } & Invalid & 626 & 3.2 & 502 & 57 & 123 \\
\hline & & & Valid & 612 & 2.9 & 492 & 54 & 120 \\
\hline & & & Difference & 14 & 0.2 & 10 & 3 & 4 \\
\hline & & & $t$ & 2.77 & 0.74 & 1.66 & 1.08 & 0.73 \\
\hline & & & $p$ & .010 & .464 & .107 & .288 & .472 \\
\hline & & & $d_{\mathrm{z}}$ & 0.50 & 0.14 & 0.30 & 0.20 & 0.13 \\
\hline \multirow[t]{6}{*}{ E3 } & \multirow[t]{6}{*}{ Variable color singleton } & \multirow[t]{6}{*}{ Color } & Invalid & 665 & 3.2 & 541 & 63 & 121 \\
\hline & & & Valid & 644 & 2.8 & 522 & 57 & 120 \\
\hline & & & Difference & 22 & 0.8 & 19 & 7 & 1 \\
\hline & & & $t$ & 5.94 & 2.24 & 7.20 & 3.54 & 0.31 \\
\hline & & & $p$ & $<.001$ & .034 & $<.001$ & .002 & .757 \\
\hline & & & $d_{\mathrm{z}}$ & 1.16 & 0.44 & 1.41 & 0.69 & 0.06 \\
\hline
\end{tabular}


Table 1 (continued)

\begin{tabular}{llllllll}
\hline Experiment & Target type & Cue type & Cue validity & $M_{\text {RT }}$ & \% error & $\mu$ & $\sigma$ \\
\hline & Onset & Invalid & 664 & 3.1 & 536 & 56 & 126 \\
& & Valid & 642 & 2.2 & 528 & 58 & 111 \\
& & Difference & 22 & 0.9 & 8 & -3 & 14 \\
& & $t$ & 4.43 & 2.26 & 1.34 & 0.62 & 2.06 \\
& & $p$ & $<.001$ & .033 & .191 & .521 \\
& & $d_{\mathrm{z}}$ & 0.87 & 0.44 & 0.26 & 0.13 \\
\hline
\end{tabular}

significant, reflecting larger cuing effects in $\mu$ by color cues than by onset cues (Table 1). The interaction was also significant in the onset target group, due to larger cuing effects for onset cues than for color cues. Thus, contingent attentional capture was observed in $\mu$, just as in the analyses of $M_{\mathrm{RT}}$.

For $\sigma$, the target type $\times$ cue validity interaction was significant, as were the cue type $\times$ cue validity interaction and the three-way interaction. The three-way interaction was examined with 2 (cue type) $\times 2$ (cue validity) ANOVAs run on the onset target group and the color target group. For the color target group, the cue type $\times$ cue validity interaction was significant, due to a larger cuing effect in $\sigma$ for color cues than for onset cues (Table 1). The interaction was not significant in the onset target group.

For $\tau$, the only significant effect was the interaction between target type and cue validity. Importantly, the three-way interaction was not significant, suggesting that contingent attentional capture did not occur in $\tau$.

To summarize, the contingent capture effects in $M_{\mathrm{RT}}$ were influenced by $\mu$, not $\tau$. This is reflected in the three-way interaction in $\mu$ and the absence of a three-way interaction in $\tau$. Also, cuing effects in $\mu$ mirrored the cuing effects in $M_{\mathrm{RT}}$, whereas there were no cuing effects in $\tau$.

\section{Vincentile analysis}

For each cell in the cue type $\times$ cue validity design, each subject's data were sorted from fastest to slowest. The first $12.5 \%$ of each subject's data were averaged, followed by the second $12.5 \%$, the third $12.5 \%$, and so on, resulting in eight quantiles (bins). The individual quantiles were then averaged with those of the other subjects in each target group. Figure 4 shows the quantile plots for the valid cue (solid line) and invalid cue (dotted line) conditions. An omnibus ANOVA $^{2}$ yielded a

\footnotetext{
$\overline{2}$ An initial ANOVA on the quantiles with CTOA included as a factor did not produce significant interactions between CTOA and the cuing effects in any experiment, $F_{\mathrm{S}}<1$, suggesting that the cuing effects in the distribution analyses for target-relevant and for target-irrelevant cues were consistent across quantiles. A corresponding analysis with CTOA was not possible for the ex-Gaussian analysis, since there would have been too few observations per subject per condition for reliable parameter estimates.
}

nonsignificant target type $\times$ cue type $\times$ cue validity $\times$ RT bin interaction, $F(1.41,55.10)=1.93, M S E=1,573.55, p=.165$, $\eta_{\mathrm{p}}^{2}=.05$, suggesting that the cuing effects were stable across quantiles in each target type $\times$ cue type combination. The nonsignificant ANOVA replicates the ex-Gaussian analysis and suggests that the contingent capture effects in $M_{\mathrm{RT}}$ were due to differences in $\mu$ (shifting), not differences in $\tau$ (skewing).

Although the four-way interaction was not significant, the bin $\times$ cue validity interaction was assessed for each target type $\times$ cue type combination. Table 5 lists the results of each ANOVA. The only significant interaction was in the color-target/color-cue condition, reflecting a smaller cuing effect at the eighth bin, as compared with stable cuing effects at the other seven bins. Otherwise, the cuing effects were stable across latency, which is consistent with the lack of a skewing effect from the ex-Gaussian analysis.

\section{Discussion}

Cuing effects in $M_{\mathrm{RT}}$ were larger for target-relevant cues than for target-irrelevant cues, reflecting contingent attentional capture. Importantly, the ex-Gaussian analysis showed that the target type $\times$ cue type $\times$ cue validity interaction in $M_{\mathrm{RT}}$ was due to an interaction in $\mu$, not $\tau$. This suggests that distribution shifting, not skewing, was responsible for the contingent attentional capture effects, and the quantile plots and corresponding analyses support the findings in the ex-Gaussian analysis. As will be elaborated later, the results support the contingent orienting hypothesis and do not support the disengagement account.

\section{Experiment 2}

Experiment 1 showed that top-down control influences cuing effects through distribution shifting $(\mu)$, not skewing $(\tau)$. Experiment 2 extended these results by examining whether an attentional set for a highly specific feature would modulate cuing effects through $\mu$. In Experiment 2, the target was a specific color among heterogeneous nontarget colors. Specifically, the target was red for some subjects and blue for 
Table 2 Results of ANOVAs on RTs and percentages of errors in Experiments 1-3

\begin{tabular}{|c|c|c|c|c|c|c|c|c|c|c|c|}
\hline \multirow[t]{2}{*}{ Experiment } & \multirow[t]{2}{*}{ Effect } & \multicolumn{5}{|c|}{ Response times } & \multicolumn{5}{|c|}{ Percent errors } \\
\hline & & $F$ & $d f$ & $M S E$ & $p$ & $\eta_{\mathrm{p}}^{2}$ & $F$ & $d f$ & $M S E$ & $p$ & $\eta_{\mathrm{p}}^{2}$ \\
\hline \multirow[t]{9}{*}{1} & Target type & 12.31 & 1,39 & $17,130.41$ & $<.001$ & .24 & 0.15 & 1,39 & .003 & .697 & $<.01$ \\
\hline & Cue type & 3.93 & 1,39 & 126.72 & .055 & .09 & 0.94 & 1,39 & .001 & .339 & .02 \\
\hline & Cue validity & 108.13 & 1,39 & 189.22 & $<.001$ & .74 & 0.01 & 1,39 & .001 & .911 & $<.01$ \\
\hline & Target type $\times$ cue type & 3.19 & 1,39 & 126.72 & .082 & .08 & 0.01 & 1,39 & .001 & .909 & $<.01$ \\
\hline & Target type $\times$ cue validity & 0.16 & 1,39 & 189.22 & .688 & $<.01$ & 5.05 & 1,39 & .001 & .030 & .12 \\
\hline & Cue type $\times$ cue validity & 0.40 & 1,39 & 67.68 & .531 & .01 & 8.69 & 1,39 & .001 & .005 & .18 \\
\hline & Target type $\times$ cue type $\times$ cue validity & 30.38 & 1,39 & 169.42 & $<.001$ & .44 & 4.75 & 1,39 & .001 & .035 & .11 \\
\hline & Cue type $\times$ cue validity (color targets) & 24.58 & 1,20 & 133.35 & $<.001$ & .55 & 10.15 & 1,20 & .001 & .005 & .34 \\
\hline & Cue type $\times$ cue validity (onset targets) & 9.50 & 1,19 & 207.40 & .006 & .55 & 0.44 & 1,19 & .001 & .515 & .02 \\
\hline \multirow[t]{3}{*}{2} & Cue type & 0.85 & 1,29 & 290.27 & .434 & .03 & 1.73 & 1,29 & .001 & .186 & .06 \\
\hline & Cue validity & 59.97 & 2,58 & 370.97 & $<.001$ & .67 & 0.46 & 2,58 & .001 & .504 & .02 \\
\hline & Cue type $\times$ cue validity & 19.50 & 2,58 & 372.82 & $<.001$ & .40 & 0.97 & 2,58 & .001 & .386 & .03 \\
\hline \multirow[t]{3}{*}{3} & Cue type & 0.21 & 1,25 & 182.16 & .652 & .01 & 0.21 & 1,25 & .001 & .651 & .01 \\
\hline & Cue validity & 41.70 & 1,25 & 298.70 & $<.001$ & .62 & 7.34 & 1,25 & .001 & .012 & .23 \\
\hline & Cue type $\times$ cue validity & 0.01 & 1,25 & 196.72 & .959 & $<.01$ & 0.03 & 1,25 & .001 & .869 & $<.01$ \\
\hline
\end{tabular}

others, and each nontarget was a different color. The cue was the same color as the target (red in the red target group, blue in the blue target group), a different color than the target (blue in the red target group, red in the blue target group), or an onset. Cuing effects were expected to be larger for same-color cues than for different-color cues and onset cues. The question was whether this cue type $\times$ cue validity interaction was due to distribution shifting $(\mu)$, skewing $(\tau)$, or both.
Method

\section{Design}

The design was a 3 (cue type: same color, different color, onset cue) $\times 2$ (cue validity: valid vs. invalid) within-subjects factorial. Subjects were randomly assigned to respond to a red target $(n=16)$ or a blue target $(n=16)$. The three cue conditions were presented equally often across trials.

Table 3 Total number of trials presented per subject, the mean number of trials used per subject for the analyses, and the results of distribution fit tests in each cue condition $\times$ cue validity condition in Experiments 1-3

\begin{tabular}{|c|c|c|c|c|c|c|c|c|}
\hline \multirow[t]{2}{*}{ Cue } & \multirow[t]{2}{*}{ Trials/Subject } & \multicolumn{2}{|l|}{ Experiment 1} & \multicolumn{3}{|l|}{ Experiment 2} & \multicolumn{2}{|l|}{ Experiment 3} \\
\hline & & Color cue & Onset cue & Same-color cue & Different-color cue & Onset cue & Color cue & Onset cue \\
\hline \multirow[t]{5}{*}{ Valid } & Presented & 96 & 96 & 64 & 64 & 64 & 128 & 64 \\
\hline & Used: $M(S D)$ & $92.6(3.4)$ & $91.8(3.4)$ & $60.6(4.2)$ & $61.0(3.6)$ & $60.9(2.3)$ & $122.7(4.0)$ & $61.3(1.6)$ \\
\hline & $\begin{array}{c}\text { Kolmogorov- } \\
\text { Smirnov } D\end{array}$ & $.13 * / .12 *$ & $.10 * / .12 *$ & $.13 *$ & $.13 *$ & $.12 *$ & $.11^{*}$ & $.11 *$ \\
\hline & $\bar{\chi}^{2}$ & $6.62 / 6.61$ & $7.75 / 7.06$ & 4.36 & 4.11 & 4.98 & 4.65 & 2.93 \\
\hline & $\bar{\chi}_{p}^{2}$ & $.36 / .50$ & $.26 / .11$ & .36 & .25 & .17 & .32 & .40 \\
\hline \multirow[t]{5}{*}{ Invalid } & Presented & 288 & 288 & 192 & 192 & 192 & 384 & 192 \\
\hline & Used: $M(S D)$ & $275.2(8.0)$ & $276.4(8.0)$ & $181.5(7.1)$ & $181.0(8.1)$ & $182.3(7.4)$ & $364.3(10.5)$ & $182.8(5.4)$ \\
\hline & Kolmogorov-Smirnov $D$ & $.09 * / .12 *$ & $.11 * / .11 *$ & $.11 *$ & $.13^{*}$ & $.12 *$ & $.10^{*}$ & $.11^{*}$ \\
\hline & $\bar{\chi}^{2}$ & $14.45 / 16.57$ & $20.94 / 19.27$ & 13.43 & 14.29 & 15.72 & 15.43 & 15.98 \\
\hline & $\bar{\chi}_{p}^{2}$ & $.42 / .28$ & $.16 / .10$ & .26 & .16 & .11 & .22 & .14 \\
\hline
\end{tabular}

Kolmogorov-Smirnov $D$ values were obtained from the RT distributions aggregated over all subjects. The $\bar{\chi}^{2}$ values were obtained by averaging goodness-of-fit statistics obtained during fitting the ex-Gaussian to each subject's data; hence, this value is the mean goodness-of-fit statistic over all subjects. The $\bar{\chi}_{p}^{2}$ values are the exact $p$-values for each mean goodness-of-fit statistic. Under Experiment 1 , the value before the / is for the color target group, and the value after the / is for the onset target group.

$* p<.00001$ 


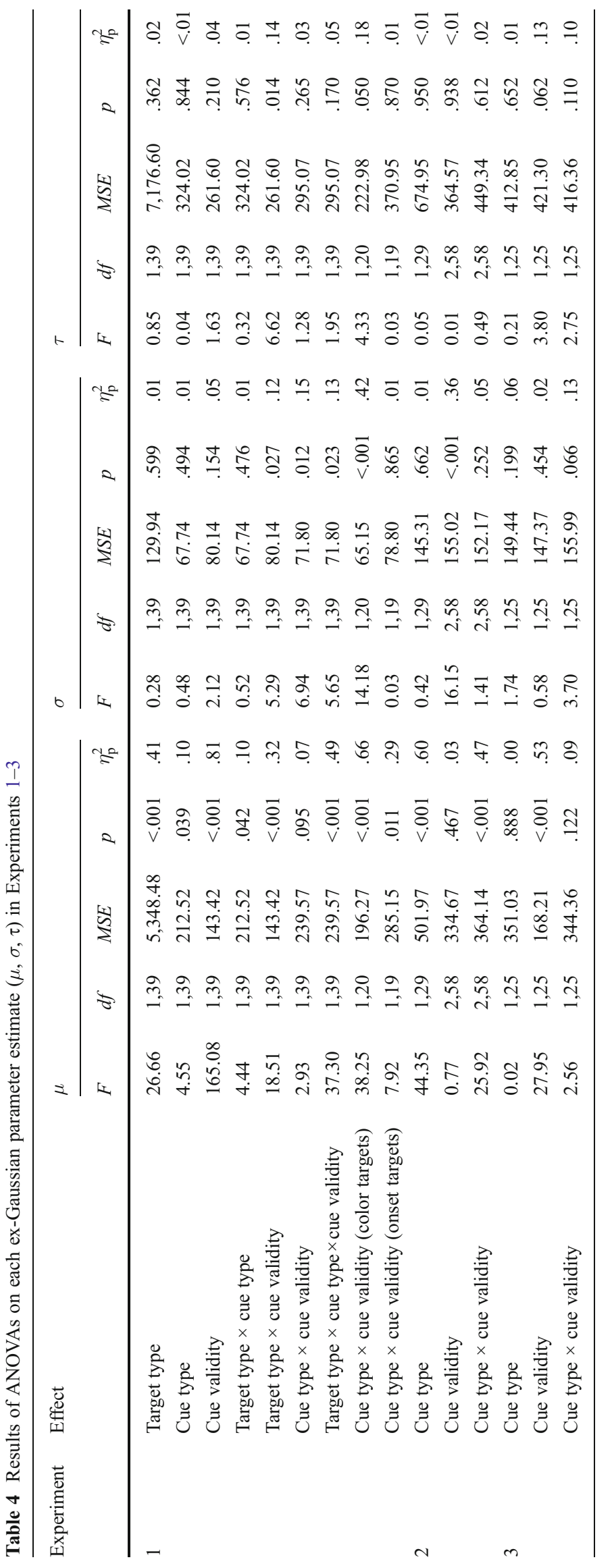


Fig. 4 Quantile plots for the color cue and onset cue conditions for each target type. The solid line is the valid cue condition, and the dotted line is the invalid cue condition. Error bars are the $95 \%$ confidence intervals based on the withinsubjects error term (Equation 2, Hollands \& Jarmasz, 2010)
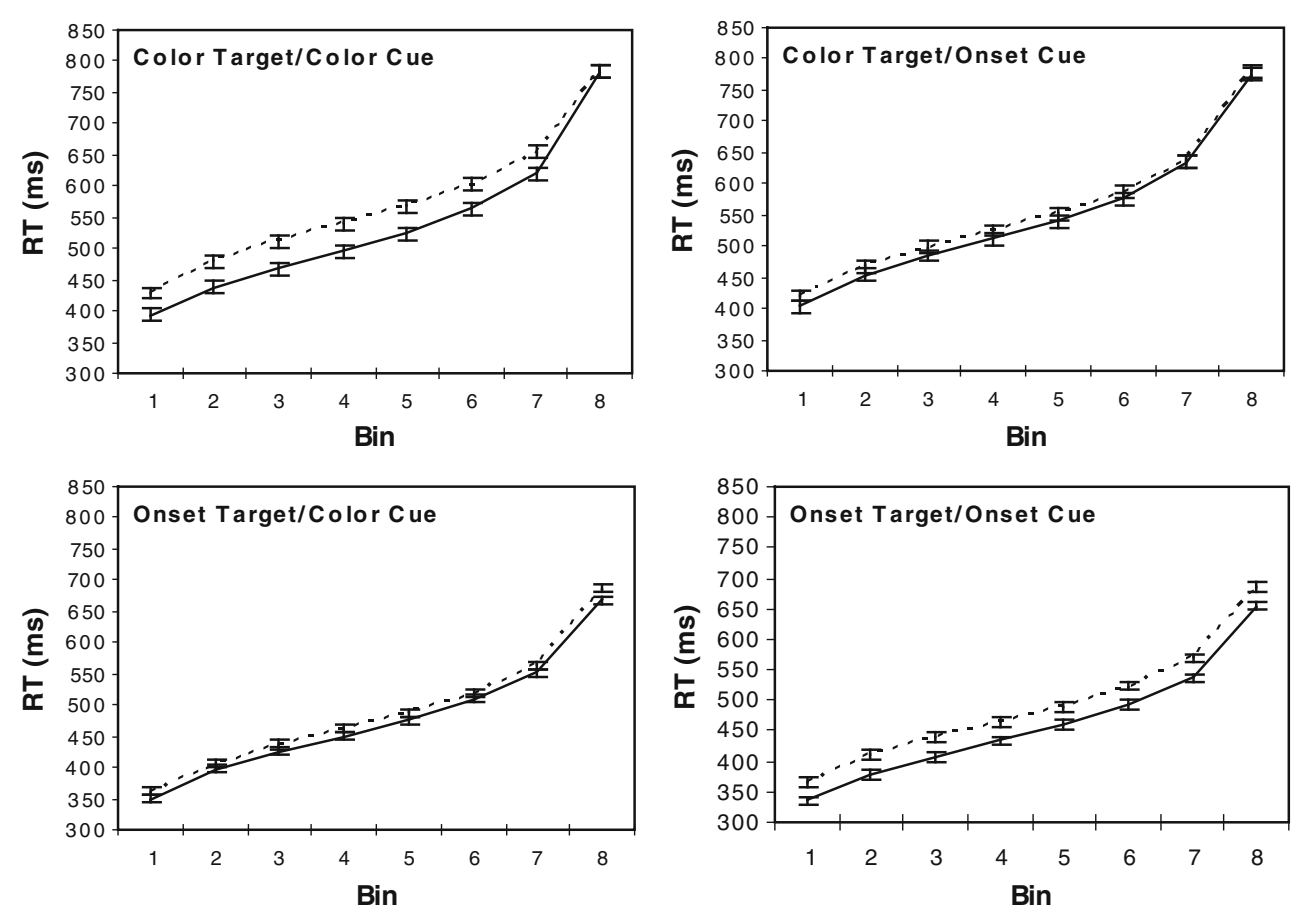

\section{Stimuli}

The cue display contained an onset cue or color cue. The color cue was a red $\left(.447, .334 ; 12.91 \mathrm{~cd} / \mathrm{m}^{2}\right)$ or a blue $(.198, .139$; $8.68 \mathrm{~cd} / \mathrm{m}^{2}$ ) box at one peripheral location, and the box at each other placeholder was green. For subjects who saw a red target, the red cue was designated the same-color cue, and the blue cue was the different-color cue. Cue assignment was reversed for subjects who saw the blue target.

Each target display included one blue item or one red item, which designated the target. Nontargets were randomly assigned to be one of three colors: teal $(.228, .339 ; .72 \mathrm{~cd} /$ $\left.\mathrm{m}^{2}\right)$, purple $\left(.321, .154 ; 11.15 \mathrm{~cd} / \mathrm{m}^{2}\right)$, or orange $(.480, .457$; $\left.8.66 \mathrm{~cd} / \mathrm{m}^{2}\right)$.

\section{Results}

Two subjects' data were removed due to excessive errors $\left(M_{\text {Accuracy }}<10 \%\right)$. The same trimming procedures used in Experiment 1 resulted in $5.3 \%$ of the data excluded $(3.4 \%$ due to error).

\section{RT and error analyses}

Each subject's mean RT was computed for each cell in the cue type $\times$ cue validity design, and the arithmetic mean for each cell appears in Table 1. Results of a 3 (cue type: same color, different color, onset) $\times 2$ (cue validity: valid vs. invalid) repeated measures ANOVA appear in Table 2. The ANOVA revealed a main effect of cue validity, due to faster responding in the valid condition. Importantly, the interaction was significant, reflecting a larger cuing effect by same-color cues than by different-color cues and onset cues (Table 1). The main effect of cue type was not significant.

An analysis on the error rates failed to yield significant effects.

\section{Ex-Gaussian analysis}

Kolmogorov-Smirnov tests were significantly different from normal in each condition, and average chi-square goodness-of-fit statistics showed that the RT distributions did not significantly deviate from a theoretical ex-Gaussian (Table 3). Figure 8 in the Appendix displays the exGaussian function fit to the data for each cue type $\times$ cue validity condition. As in Experiment 1, the ex-Gaussian function fits the data quite well.

Parameter estimates were obtained in the same manner as in Experiment 1, and the means appear in Table 1. Each subject's estimate for $\mu, \sigma$, and $\tau$ was entered into separate 3 (cue type) $\times 2$ (cue validity) ANOVAs, and the results of the omnibus ANOVAs are presented in Table 4.

For $\mu$, the main effect of cue validity was significant, as was the interaction. The interaction reflects a larger cuing effect in $\mu$ for same-color cues, as compared with different-color cues and onset cues (Table 1). For $\sigma$, the main effect of cue validity was significant, but the other effects were not. For $\tau$, no effect reached statistical significance. As in Experiment 1, the cuing effects in $\mu$ mirrored the cuing effects in $M_{\mathrm{RT}}$, which suggests that the cue type $\times$ cue validity interaction in $M_{\mathrm{RT}}$ was influenced by $\mu$, and not $\tau$. 
Table 5 Results of bin $\times$ cue validity ANOVAs on the vincentized data in Experiments $1-3$

\begin{tabular}{|c|c|c|c|c|c|c|c|c|}
\hline Experiment & Target type & Cue type & Effect & $F$ & $d f^{a}$ & $M S E$ & $p$ & $\eta_{\mathrm{p}}^{2}$ \\
\hline \multirow[t]{12}{*}{1} & \multirow[t]{6}{*}{ Color target } & \multirow[t]{3}{*}{ Color cue } & Bin & 117.20 & $1.08,21.50$ & $31,998.89$ & $<.001$ & .85 \\
\hline & & & Cue validity & 58.18 & 1,20 & $1,793.12$ & $<.001$ & .74 \\
\hline & & & Bin $\times$ cue validity & 4.41 & $1.58,31.62$ & $2,032.98$ & .028 & .18 \\
\hline & & \multirow[t]{3}{*}{ Onset cue } & Bin & 139.99 & $1.10,21.96$ & $25,033.52$ & $<.001$ & .88 \\
\hline & & & Cue validity & 9.93 & 1,20 & $1,005.92$ & .005 & .33 \\
\hline & & & Bin $\times$ cue validity & 0.86 & $1.47,29.38$ & $1,416.67$ & .540 & .04 \\
\hline & \multirow[t]{6}{*}{ Onset cue } & \multirow[t]{3}{*}{ Color cue } & Bin & 101.87 & $1.12,21.20$ & $24,923.61$ & $<.001$ & .84 \\
\hline & & & Cue validity & 19.19 & 1,19 & 549.10 & $<.001$ & .50 \\
\hline & & & Bin $\times$ cue validity & 0.55 & $1.80,34.22$ & 705.72 & .795 & .03 \\
\hline & & \multirow[t]{3}{*}{ Onset cue } & Bin & 140.43 & $1.14,21.60$ & $17,702.22$ & $<.001$ & .88 \\
\hline & & & Cue validity & 31.91 & 1,19 & $2,464.71$ & $<.001$ & .63 \\
\hline & & & Bin $\times$ cue validity & 0.05 & $1.23,23.38$ & $1,714.28$ & .866 & $<.01$ \\
\hline \multirow[t]{9}{*}{2} & \multirow[t]{9}{*}{ Color target } & \multirow[t]{3}{*}{ Same color } & Bin & 144.60 & $1.05,30.52$ & $55,534.70$ & $<.001$ & .83 \\
\hline & & & Cue validity & 75.58 & 1,29 & $3,491.53$ & $<.001$ & .72 \\
\hline & & & Bin $\times$ cue validity & 1.20 & $1.70,49.28$ & $2,350.95$ & .303 & .04 \\
\hline & & \multirow[t]{3}{*}{ Different color } & Bin & 127.53 & $1.05,30.53$ & $62,526.26$ & $<.001$ & .82 \\
\hline & & & Cue validity & 1.53 & 1,29 & $2,124.72$ & .227 & .05 \\
\hline & & & Bin $\times$ cue validity & 0.41 & $1.77,51.25$ & $1,267.79$ & .898 & $<.01$ \\
\hline & & \multirow[t]{3}{*}{ Onset cue } & Bin & 150.34 & $1.07,31.04$ & $53,388.98$ & $<.001$ & .84 \\
\hline & & & Cue validity & 7.07 & 1,29 & $3,123.50$ & .013 & .20 \\
\hline & & & Bin $\times$ cue validity & 0.41 & $1.59,46.16$ & $1,923.27$ & .622 & .01 \\
\hline \multirow[t]{6}{*}{3} & \multirow[t]{6}{*}{ Variable color singleton } & \multirow[t]{3}{*}{ Color cue } & Bin & 233.74 & $1.07,26.73$ & $29,403.54$ & $<.001$ & .90 \\
\hline & & & Cue validity & 33.42 & 1,25 & $1,431.71$ & $<.001$ & .57 \\
\hline & & & Bin $\times$ cue validity & 1.71 & $1.61,40.26$ & 772.66 & .198 & .06 \\
\hline & & \multirow[t]{3}{*}{ Onset cue } & Bin & 175.42 & $1.06,26.59$ & $38,261.97$ & $<.001$ & .88 \\
\hline & & & Cue validity & 19.06 & 1,25 & $2,598.36$ & $<.001$ & .43 \\
\hline & & & Bin $\times$ cue validity & 2.85 & $1.92,48.09$ & $1,746.22$ & .070 & .10 \\
\hline
\end{tabular}

${ }^{a}$ Greenhouse-Geisser correction was applied where spherecity was violated.

\section{Vincentile analysis}

Vincentiles were calculated in the same manner as in Experiment 1 . Figure 5 shows the quantile plots for the valid and invalid cue conditions for each cue type. An omnibus ANOVA with factors cue type, cue validity, and RT bin produced a nonsignificant cue type $\times$ cue validity $\times$ RT bin interaction, $F<1$. As in Experiment 1 , the bin $\times$ cue validity interaction was evaluated for each cue type, and the results of each ANOVA appear in Table 5. To summarize, the cue validity $\times$ RT bin interaction did not approach significance for any cue type; thus, the cuing effects were stable across quantile, which is consistent with a shifting effect and the lack of a skewing effect in the ex-Gaussian analysis.

\section{Discussion}

Experiment 2 replicated the contingent attentional capture effects in $M_{\mathrm{RT}}$ in Experiment 1, and importantly, the ex-Gaussian analysis showed that the cue type $\times$ cue validity interaction in $M_{\mathrm{RT}}$ was influenced by $\mu$, not by $\tau$. Also, cuing effects in $\mu$ mimicked those in $M_{\mathrm{RT}}$ and were absent in $\tau$. Thus, larger cuing effects by samecolor cues versus smaller cuing effects by different-color cues and onset cues reflected differences in distribution shifting, not skewing.

\section{Experiment 3}

In Experiments 1 and 2, the target's feature was constant across trials. The questions addressed in Experiment 3 were (1) whether the cuing effects for onset cues and color cues would be equivalent if the target's color was randomized across trials, and (2) how the ex-Gaussian parameters would contribute to the cuing effects. In Experiment 3, the target was unpredictably red, blue, teal, purple, or orange, so subjects could not search for a specific color and had to adopt a singleton detection mode (Bacon \& 

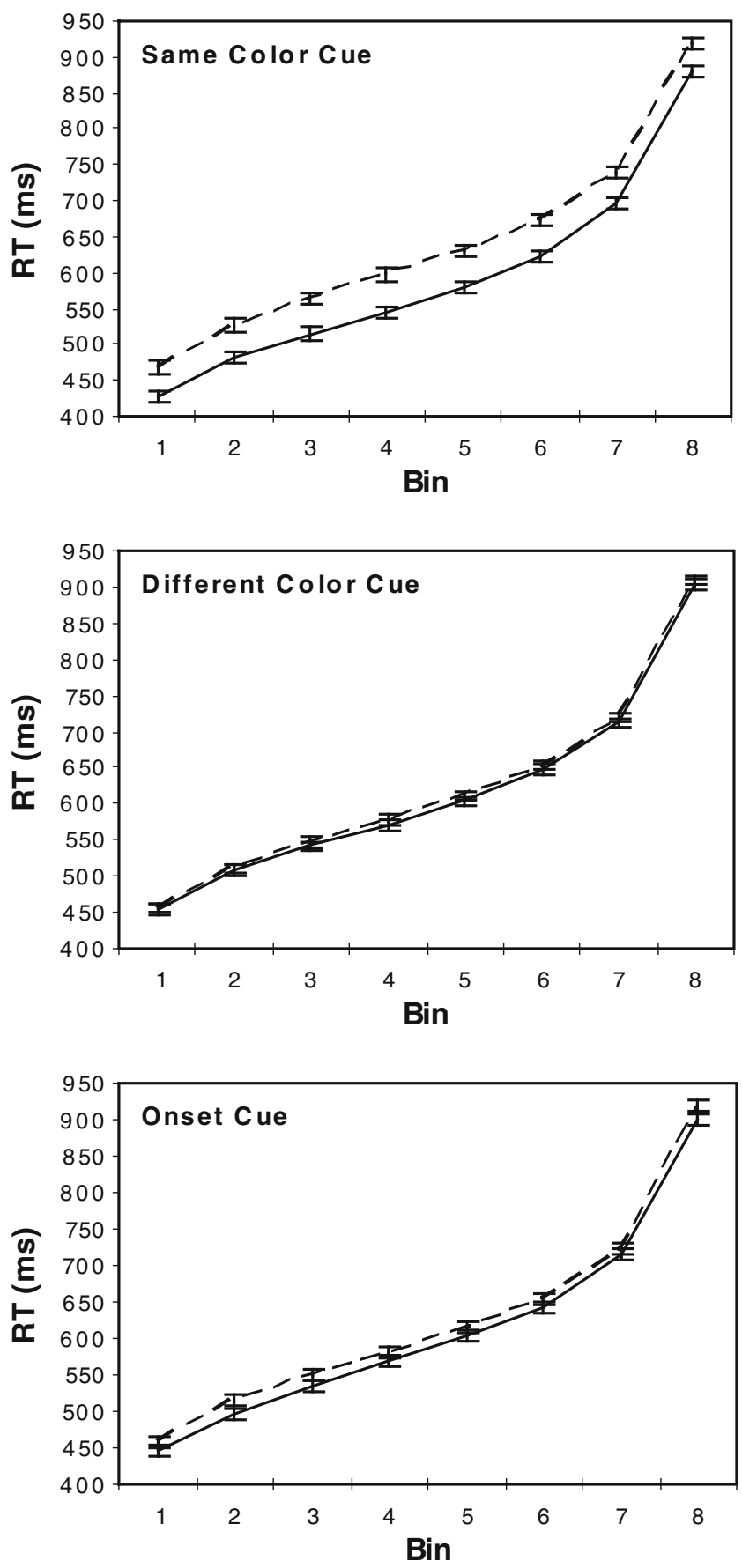

Fig. 5 Quantile plots for the congruent color, incongruent color, and onset cue conditions. The solid line is the valid cue condition, and the dotted line is the invalid cue condition. Error bars are $95 \%$ confidence intervals based on the within-subjects error term (Equation 2, Hollands \& Jarmasz, 2010)

Egeth, 1994; Pashler, 1988). The cue was a color singleton or onset singleton. Because both cues were relevant to the target's status as a singleton, it was possible, and observed, that both cues would capture attention. The question was how the ex-Gaussian parameters would contribute to the cuing effects in $M_{\mathrm{RT}}$.
Method

Design

The design was a 2 (cue type: color vs. onset) $\times 2$ (cue validity: valid vs. invalid) within-subjects factorial.

Stimuli

The cue display contained an onset cue or a color cue (red or blue). The target display included three nontarget gray items and one colored target item. The target's color varied across trials between red, blue, teal, purple, and orange.

Results

One subject's data were removed due to excessive errors $\left(M_{\text {Accuracy }}<20 \%\right)$. The trimming procedures used in Experiment 1 resulted in $4.8 \%$ of the data being excluded (3.0\% due to error).

Because the target's color varied, the target's color on the preceding trial may have moderated cuing effects on the current trial. ${ }^{3}$ That is, cuing effects by red cues and blue cues may have benefitted when a red or blue target appeared on the preceding trial, rather than an orange, teal, or purple target (intertrial priming; Maljkovic \& Nakayama, 1994). Similarly, red cues and blue cues may have benefitted target localization within a trial when the target was also red or blue, but not orange, teal, or purple (within-trial priming).

To examine within-trial and intertrial priming effects, the data were first analyzed in a 2 (preceding target: similar vs. dissimilar) $\times 2$ (current target: similar vs. dissimilar) $\times 2$ (cue validity: valid vs. invalid) repeated measures ANOVA, where similar targets were red or blue and dissimilar targets were orange, teal, or purple. The analysis yielded a main effect of current target, $F(1,25)=45.48, M S E=554.17$, $p<.0001, \eta_{\mathrm{p}}^{2}=.64$, with faster responses to the similar targets, and a main effect of cue validity, $F(1,25)=14.22, M S E=$ $1,153.61, p<.001, \eta_{\mathrm{p}}^{2}=.36$. The current target $\times$ cue validity interaction was significant, suggesting within-trial priming, $F$ $(1,25)=12.17, M S E=442.28, p<.002, \eta_{p}^{2}=.33$. This interaction reflects a larger cuing effect when the current target color was dissimilar to the cue $(28 \mathrm{~ms}), F$ $(1,25)=34.31, p<.0001, \eta_{\mathrm{p}}^{2}=.58$, than when similar to the cue $(8 \mathrm{~ms}), F(1,25)=1.49, p=.233, \eta_{\mathrm{p}}^{2}=.06$. No other effects were significant [preceding target, $F(1$, $25)=3.19, M S E=762.98, p=.086, \eta_{\mathrm{p}}^{2}=.11$; three-

\footnotetext{
${ }^{3}$ I thank Ulrich Ansorge for suggesting the following analyses.
} 
way, $F(1,25)=1.19, M S E=494.84, p=.286, \eta_{\mathrm{p}}^{2}=.04$; all other $\left.F_{\mathbf{S}}<1\right]$, suggesting no intertrial priming.

Although this confirms within-trial priming, it is unlikely that the results reflect sensory priming from the cue to the target. This is so because studies indicate that sensory priming from a cue to a target is observed when cuing effects by similar (matching) cues are larger than cuing effects for dissimilar (nonmatching) cues within a trial (e.g., Ansorge \& Horstmann, 2007; Worschech \& Ansorge, 2012). The results of Experiment 3 clearly showed the opposite. The following analyses were performed without excluding conditions that may have benefitted from within-trial priming (current target similar), because (1) excluding the current target similar condition removes $40 \%$ of the data in the color cue condition, which would affect parameter estimates; (2) while current similar color targets may have benefitted from color cues, it is just as likely that dissimilar targets did not benefit, so it is unclear which condition is more appropriate to exclude; and (3) analyses without the current target similar condition produced the same pattern. ${ }^{4}$

\section{$R T$ and error analyses}

Each subject's mean RT was computed for each cell in the cue type $\times$ cue validity design, and arithmetic means appear in Table 1. Results of a 2 (cue type: color vs. onset) $\times 2$ (cue validity: valid vs. invalid) repeated measures ANOVA are presented in Table 2. The ANOVA revealed a main effect of cue validity. The main effect of cue type and the interaction were not significant.

A corresponding ANOVA on the error rates yielded a main effect of cue validity. No other effects were significant.

\section{Ex-Gaussian analysis}

Kolmogorov-Smirnov tests on the aggregate distributions were significantly different from normal, and average chi-square goodness-of-fit statistics showed that the distributions did not significantly deviate from a theoretical ex-Gaussian (Table 3). Figure 9 in the Appendix displays the ex-Gaussian function fit to the data across for each cue type $\times$ cue validity combination. As in Experiments 1 and 2, the ex-Gaussian function fits the data very well. The ex-Gaussian parameter estimates are presented in Table 1 , and each subject's estimate for $\mu, \sigma$, and $\tau$ was entered

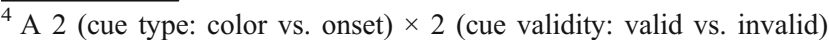
ANOVA without the red cue trials and blue cue trials produced a main effect of cue type, $F(1,25)=20.56, M S E=148.05, p<.001, \eta_{\mathrm{p}}^{2}=.45$, due to faster responding following onset cues $(653 \mathrm{~ms})$ than following color cues (664 ms), and a main effect of cue validity, $F(1,25)=46.39$, $M S E=351.46, p<.001, \eta_{\mathrm{p}}^{2}=.65$. The interaction was not significant, $F(1,25)=1.35, M S E=175.66, p=.257, \eta_{\mathrm{p}}^{2}=.05$.
}

into a separate 2 (cue type) $\times 2$ (cue validity) ANOVA. Results of the omnibus ANOVAs are presented in Table 4.

For $\mu$, only the main effect of cue validity was significant. For $\sigma$, the interaction was marginally nonsignificant, and the other effects were not significant. For $\tau$, the main effect of cue validity was marginally nonsignificant, and the other effects were not significant. The lack of a cue type $\times$ cue validity interaction in $M_{\mathrm{RT}}$ may be due to the lack of similar interactions in $\mu$ and in $\tau$. However, inspection of the cuing effects in $\mu$ and $\tau$ (Table 1) suggests that the lack of an interaction in $M_{\mathrm{RT}}$ may be due to opposing influences of $\mu$ and $\tau$ : For color cues, the cuing effect was larger in $\mu$ than in $\tau$, whereas for onset cues the cuing effect was larger in $\tau$ than in $\mu$.

\section{Vincentile analysis}

Figure 6 shows the quantile plots for the valid and invalid cue conditions for each cue type. An omnibus ANOVA with the factors cue type, cue validity, and RT bin produced a marginally nonsignificant cue type $\times$ cue validity $\times$ RT bin interaction, $F(1.98,49.54)=3.17, M S E=1,062.39, p=$ $.051, \eta_{\mathrm{p}}^{2}=.11$. The interaction does not stand out in the plots but might reflect a sharp increase in the cuing effect for onset cues at bin 8 , as compared with the relatively stable cuing effects across all eight bins for color cues.

The bin $\times$ cue validity interaction was examined for each cue type, and Table 5 lists the results of each ANOVA. For color cues, the main effect of cue validity was significant. For onset cues, the main effect of cue validity was significant, and the interaction was marginally nonsignificant. Thus, the marginal cue type $\times$ cue validity $\times$ RT bin interaction was due to an increase in cuing effect for onset cues at the longest response latency, as compared with no changes in cuing effects across latency for the color cues.

\section{Discussion}

The results differed from those in Experiments 1 and 2 in several ways. First, both color cues and onset cues elicited equivalent cuing effects in $M_{\mathrm{RT}}$, consistent with the adoption of a singleton detection mode. Second, while the contingent capture effects in $M_{\mathrm{RT}}$ in Experiments 1 and 2 reflected an influence from $\mu$ and not $\tau$, in Experiment 3 the lack of a cue type $\times$ cue validity interaction in $M_{\mathrm{RT}}$ may be due to opposing influences of $\mu$ and $\tau$ (Table 1). Specifically, the 22-ms cuing effect for color cues was due to a 19-ms influence of $\mu$ combined with a 1-ms influence of $\tau$, whereas the 22-ms cuing effect for onset cues was due to an 8 -ms influence of $\mu$ combined with a 14-ms influence of $\tau$. Note that the influence of $\tau$ was not in the direction predicted by the disengagement account, which assumes that the influence of $\tau$ will counteract the influence of $\mu$ and reduce the cuing effect ( $\tau_{\text {Invalid }}-\tau_{\text {Valid }}<0$; Fig. 2). Also, the disengagement account assumes that all salient stimuli capture attention, so the cuing 
Fig. 6 Quantile plots for the color cue and onset cue conditions. The solid line is the valid cue condition, and the dotted line is the invalid cue condition. Error bars are $95 \%$ confidence intervals based on the within-subjects error term (Equation 2, Hollands \& Jarmasz, 2010)

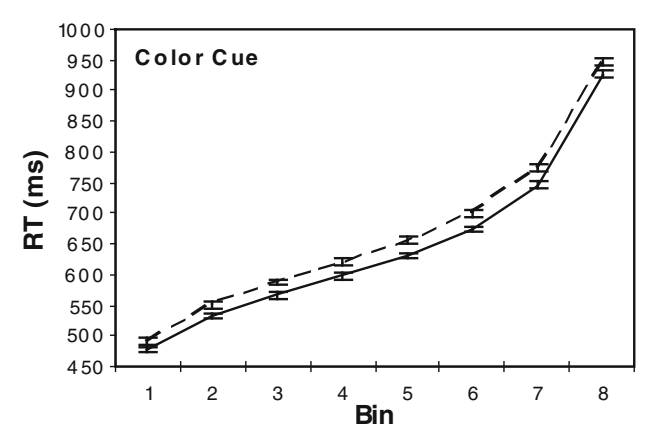

effect in $\mu$ should have been equivalent for color cues and onset cues, which was not the case.

What explains the small influence of $\tau$ and the reduced influence of $\mu$ in the onset cuing effects? The nonsignificant cue type $\times$ cue validity interaction in $\tau$ appears to reflect a smaller skewing effect $(111 \mathrm{~ms})$ for valid onset cues. It is possible that this small value of $\tau$ is a fluke, since 1 subject showed very small skew $(\tau=24 \mathrm{~ms})$. When that subject's data were removed, the mean of $\tau$ increased to $115 \mathrm{~ms}$, and the cue type $\times$ cue validity interaction was reduced in significance $(p=$ $.204)$, and the same was true for the interaction in $\mu(p=.220)$. Hence, the influence of $\tau$ does not appear to be reliable. But even with this subject's data removed, the onset cuing effect in $\mu$ increased slightly $\left(\mu_{\text {Invalid }}-\mu_{\text {Valid }}=10 \mathrm{~ms}\right)$ and in $\tau$ is reduced only slightly $\left(\tau_{\text {Invalid }}-\tau_{\text {Valid }}=11 \mathrm{~ms}\right)$. Thus, attentional capture by onsets does not appear to be as strong as that by color cues.

One speculation is that although both color cues and onset cues were target relevant, the color cues were more relevant, because they were singletons in the color dimension. As such, one may predict smaller cuing effects in $\mu$ by the onset cue, which was observed (Müller, Reimann, \& Krummenacher, 2003; Wei, Lü, Müller, \& Zhou, 2008). The question is why $\tau$ inflated the onset cuing effect. The small cuing effect in $\tau$ may reflect a postperceptual decision to shift attention to the onsetcued location. But if so, similar effects should have been found in Experiments 1 and 2, which was not the case. A more parsimonious explanation is that the larger cuing effect in $\tau$ and the smaller cuing effect in $\mu$ is a type I error, since cuing effects in $\tau$ were not observed for the same onset cues in Experiments 1 and 2. Indeed, 2 subjects, including the one above, had cuing effects in $\mu$ that were over two standard deviations below the mean. When their data were removed, the onset cuing effect in $\mu$ was $13 \mathrm{~ms}$, and in $\tau$ was $7 \mathrm{~ms}$. Importantly, there was no change to the color cuing effects in $\mu$ $(17 \mathrm{~ms})$ or $\tau(3 \mathrm{~ms})$, and the cue type $\times$ cue validity interaction no longer approached significance in $\mu(p=$ $.460)$ or $\tau(p=.419)$. In short, when considering individual differences, the cuing effects for the color cues and onset cues were driven primarily by distribution shifting $(\mu)$, not skewing $(\tau)$.

\section{General discussion}

This study performed a traditional analysis on $M_{\mathrm{RT}}$ and exGaussian and vincentizing analyses on RT distributions in three experiments that examined contingent attentional capture. In Experiments 1 and 2, the target-defining feature modulated the capture of attention, since cuing effects in $M_{\mathrm{RT}}$ were larger for target-relevant cues than for target-irrelevant cues. In Experiment 3 , the cuing effects were the same magnitude for color cues and onset cues when the target was a variable color singleton. The results are consistent with top-down attentional control moderating the shifting of attention toward salient stimuli.

The important results came from the ex-Gaussian analyses, which examined how top-down control influenced the shift and skew of RT distributions for validly and invalidly cued targets. Across experiments, cuing effects in $M_{\mathrm{RT}}$ were found to be due to distribution shifting $(\mu)$, not skewing $(\tau)$. In Experiments 1 and 2, the cue/target similarity $\times$ cuing effect interaction in $M_{\mathrm{RT}}$ was driven by a similar interaction in $\mu$ and no interaction in $\tau$, suggesting that contingent attentional capture reflects differences in distribution shifting between target-relevant and target-irrelevant cues. This can be seen in the cuing effects in $\mu$, which were similar to the cuing effects in $M_{\mathrm{RT}}$ and were absent in $\tau$. The vincentile analyses support this, because cuing effects did not change across response latency for target-relevant and targetirrelevant cues. In short, top-down modulation on the cuing effects was due to distribution shifting, not skewing.

One odd result was in Experiment 3, in which both $\mu$ and $\tau$ seemed to contribute to the null cue type $\times$ cue validity interaction in $M_{\mathrm{RT}}$. As was mentioned, it is likely that the cuing effect in $\tau$ and the smaller cuing effect in $\mu$ for onset cues in Experiment 3, relative to Experiments 1 and 2, was a type I error driven by 2 subjects with onset cuing effects in $\mu$ that were at least two standard deviations below the mean. As such, the cuing effects in $M_{\mathrm{RT}}$ in Experiment 3 also seemed to reflect a distribution shifting effect, not a skewing effect.

The contingent orienting hypothesis assumes that the cue/ target similarity $\times$ cuing effect interaction in $M_{\mathrm{RT}}$ reflects topdown control exerting its influence prior to selection and seems to predict the interaction in $M_{\mathrm{RT}}$ is driven by $\mu$, not $\tau$. In contrast, the disengagement account assumes that the cue/target 
similarity $\times$ cuing effect interaction in $M_{\mathrm{RT}}$ reflects top-down control exerting its influence after a salient cue captures attention. Hence, the disengagement account would seem to predict that the interaction in $M_{\mathrm{RT}}$ is driven by $\tau$, not $\mu$, with the influence of $\tau$ counteracting the influence of $\mu$ for targetirrelevant cues. The ex-Gaussian analyses clearly show that the cue/target similarity $\times$ cuing effect interaction in $M_{\mathrm{RT}}$ in Experiments 1 and 2 was driven by $\mu$, not $\tau$, and that cuing effects in $\mu$ mimicked those in $M_{\mathrm{RT}}$, whereas cuing effects were absent in $\tau$. Thus, the results support the contingent orienting hypothesis and suggest that top-down modulation of attentional capture occurs prior to selection of salient stimuli, not after selection.

Why does the contingent orienting hypothesis predict contingent capture effects to reflect differences in distribution shifting? The hypothesis assumes that top-down control will influence a single operation at a single point in timethat is, attention shifting toward a salient item. Stated differently, the hypothesis does not assume that top-down control exerts an influence on selective attention over time or after attention has been captured during a trial; rather, it assumes that top-down control exerts an influence before selection and before attention can be captured. If attention shifts toward a target's location in response to a cue, as with target-relevant cues, this facilitates overall responding and translates to a leftward shift in the RT distribution for valid cues. If attention does not shift toward a cue, as with targetirrelevant cues, selection does not occur, and there is no difference in processing targets preceded by valid cues or invalid cues. Thus, there should be no shifting or skewing of the RT distribution following target-irrelevant cues.

A similar question is why the disengagement account predicts both shifting and skewing to underlie contingent attentional capture effects. The disengagement account assumes that top-down control exerts its influence after attention has been captured; thus, two processes operate over time. First, a salient cue elicits a shift of attention toward its location. Second, if the cue is target irrelevant, the capture of attention is followed by a disengagement of attention. Because the two processes occur at different points over time, intuitively, these should influence different portions of an RT distribution: Attentional capture may influence $\mu$, and disengagement may influence $\tau$. It may also be that the disengagement of attention away from a cued location slows responding to a target at that same location, similar to an inhibition-of-return effect. This would increase skew in the valid cue condition, relative to the invalid condition $\left(\tau_{\text {Valid }}>\tau_{\text {Valid }}\right.$ ), because an increase in the longer RTs is more likely following valid cues. In either case, if the account is correct, $\tau$ should influence the contingent capture effects, which was not the case. Similar reasoning has been used to show when more than one cognitive process is operating on word recognition. For example, Yap et al. (2006; see also Balota et al., 2008) used ex-Gaussian analyses to show when one (vs. two) process was operating on semantic priming, and Tse, Hutchison and $\mathrm{Li}$ (2011) recently used vincentile analyses to show that two processes contributed to negative priming (inhibition and episodic retrieval). The present study adds to these by showing that contingent attentional capture reflects differences in distribution shifting, not skewing.

Some questions remain, and new research will be forthcoming. First, the negative cuing effects observed by Belopolsky et al. (2010) were interpreted to reflect capture, followed by disengagement, but could reflect a suppression of attention from being captured. Distribution analyses could resolve the issue, with the disengagement account predicting that $\tau$ will contribute to the negative cuing effects. Second, which ex-Gaussian parameters contribute to attentional capture effects in the additional singleton task? Analyses from studies conducted in my lab suggest that only $\mu$ contributes. Third, one issue in concluding that these results do not support the disengagement account is the reliance on null cuing effects in $\tau$ and $\mu$ for target-irrelevant cues. Proponents of the disengagement account could postulate that null cuing effects in $\tau$ and $\mu$ do not imply that the cue did not capture attention. But if a cue does capture attention, there should be an influence somewhere on an RT distribution. Finally, and related to the last point, is $\mu$ sensitive to stimulus-driven capture, and is $\tau$ sensitive to disengagement? Mapping cognitive operations onto parameters is debatable (Luce, 1986), although $\mu$ does appear to be sensitive to stimulus-driven processes and $\tau$ appears to be sensitive to attention-demanding processes (e.g., Balota \& Yap, 2011; Balota et al., 2008; Heathcote et al., 1991; Mewhort, Braun, \& Heathcote, 1992; Ratcliff, 1979; Yap et al., 2006, among others). Planned research will investigate the need to disengage from attention-capturing items. For example, by blocking valid and invalid cue conditions (e.g., Folk et al., 1992, Experiments 1 and 2), the cue is a reliable predictor for where the target will and will not appear, respectively, and there is a need to disengage attention from invalid cues. Thus, a disengagement effect in $\tau$ should be revealed in the invalid condition. The issue is that with $100 \%$ valid or invalid cues, shifts of attention toward a cue would not necessarily be involuntary, as with cues that are unreliable predictors of the target's location.

\section{Conclusions}

This study replicated the finding that target-defining features moderate cuing effects. Distribution analyses showed that the pattern of contingent attentional capture was driven by the $\mu$ component of an ex-Gaussian function, not by $\tau$. This indicates that differences in distribution shifting, not skewing, are responsible for contingent attentional capture in $M_{\mathrm{RT}}$. The results support Folk et al.'s (1992) contingent 
orienting hypothesis, which states that top-down modulation occurs prior to selection of salient stimuli. The results do not support the attentional disengagement account, which asserts that attentional settings modulate when attention will be disengaged from an attention-capturing item (Belopolsky et al., 2010; Theeuwes, 2010; Theeuwes et al., 2000). This study points to the utility of analyzing both central tendency and RT distributions in attention-related studies, since specific predictions from competing hypotheses can be entertained, which may not be possible by relying on measures of central tendency alone.

Author Note I thank Antony Delliturri, Nina Muto, and Alexandra Wieczorek for assistance with data collection. Experiment 1 was previously published under the title "Relationship Between Working Memory Capacity and Contingent Involuntary Orienting" in Visual Cognition

\section{Appendix}

Figs. 7, 8 and 9

Color Target

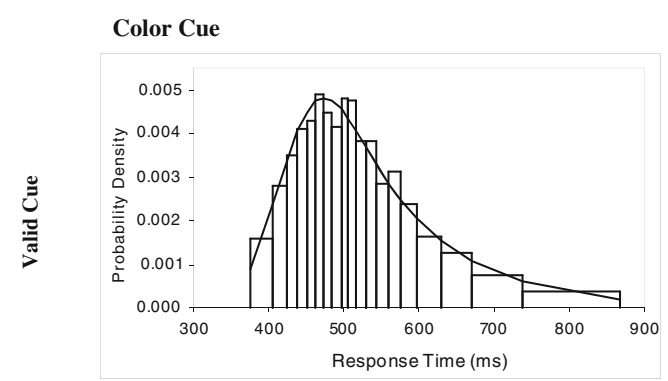

Onset Cue
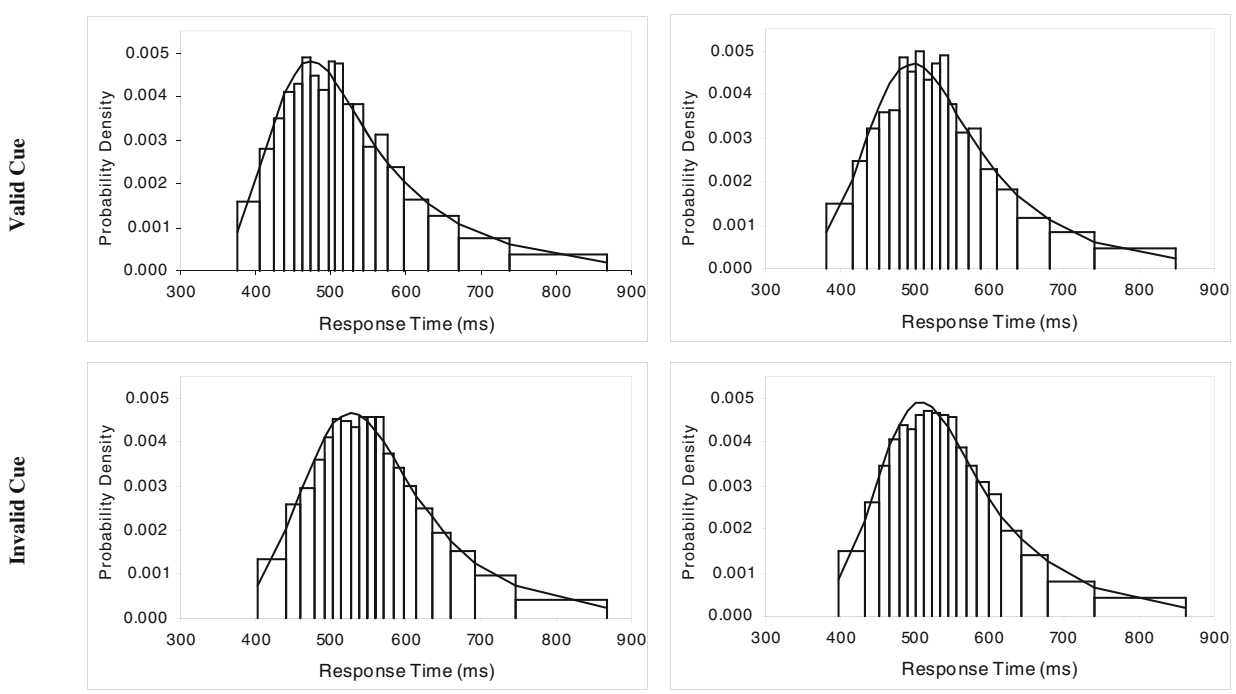

Onset Target

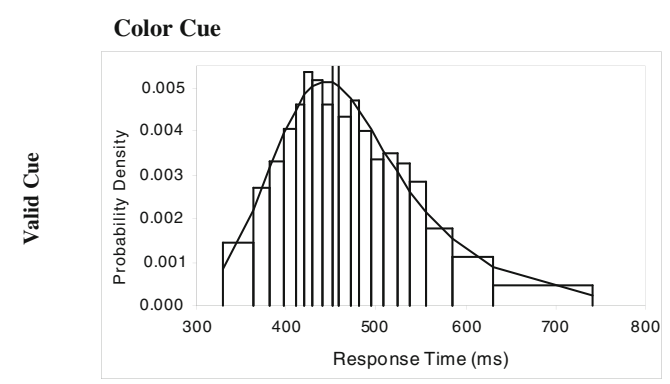

Onset Cue
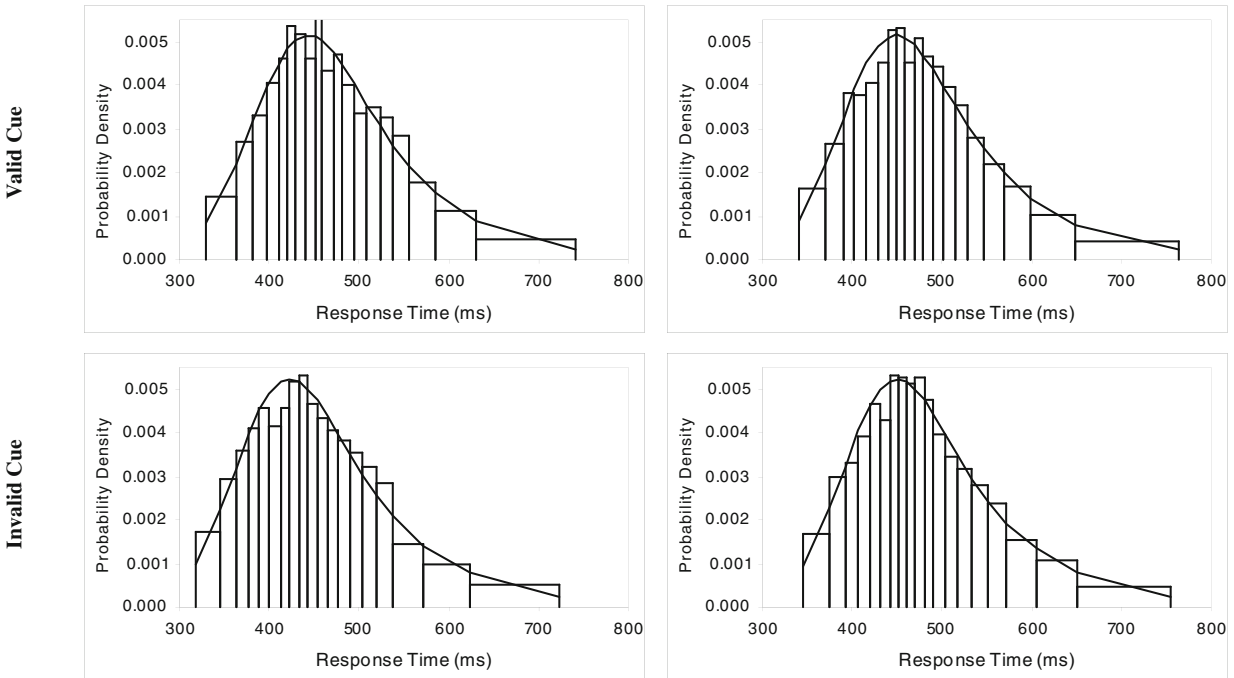

Fig. 7 Fits of the ex-Gaussian function to the data from Experiment 1, as a function of target type, cue type, and cue validity 


\section{Same Color Cue}

Valid Cue

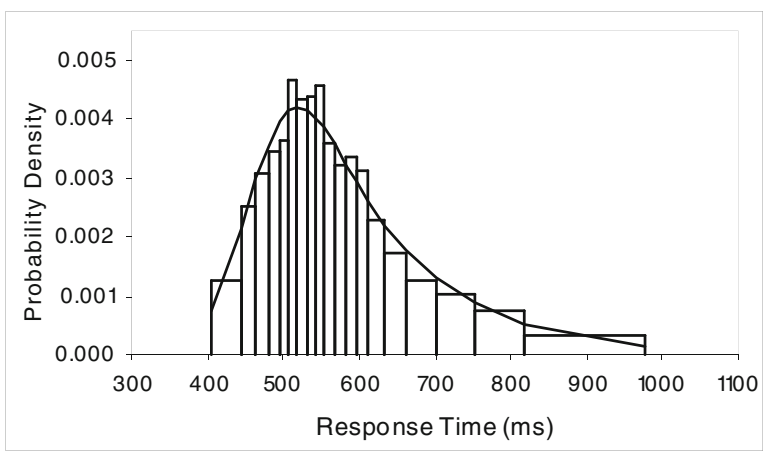

\section{Invalid Cue}

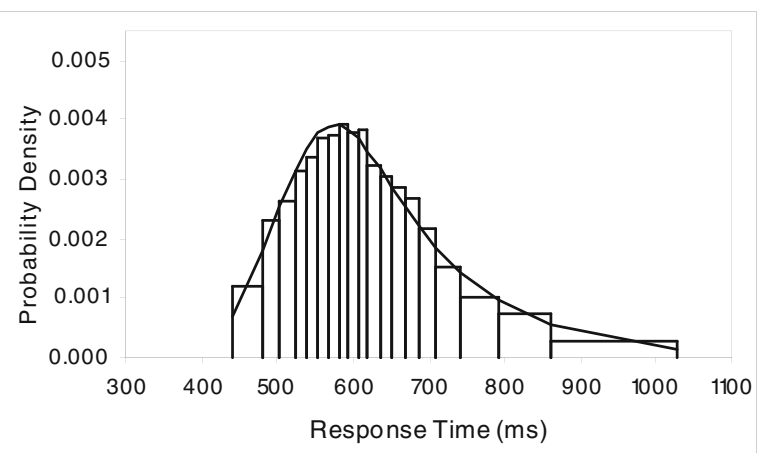

\section{Different Color Cue}

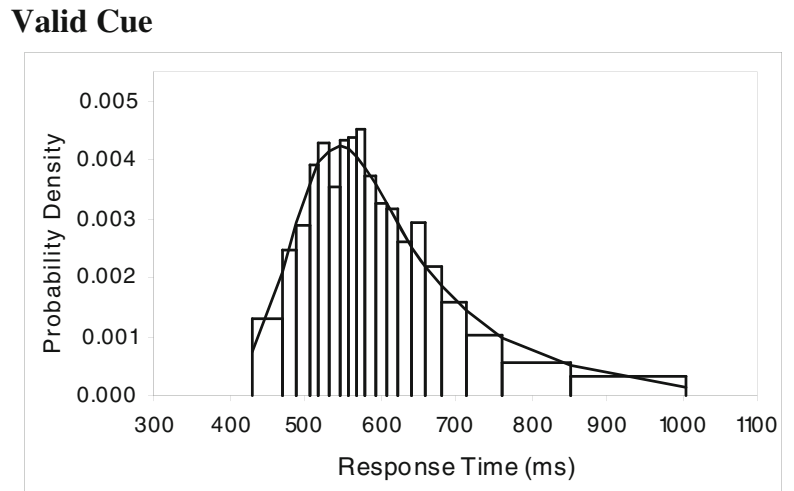

\section{Invalid Cue}

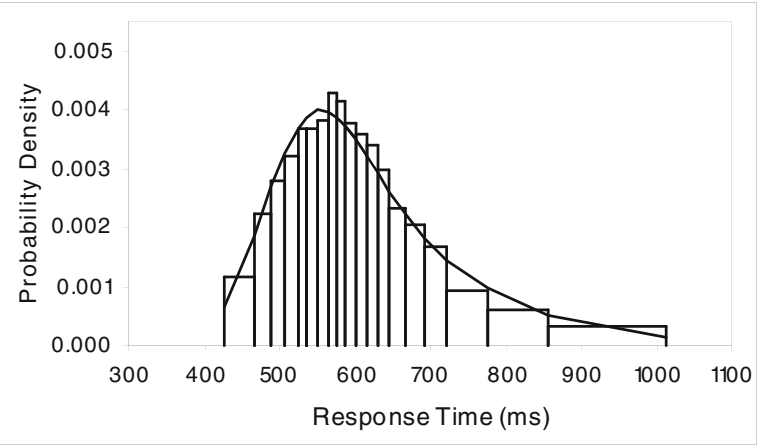

\section{Onset Cue}

Valid Cue

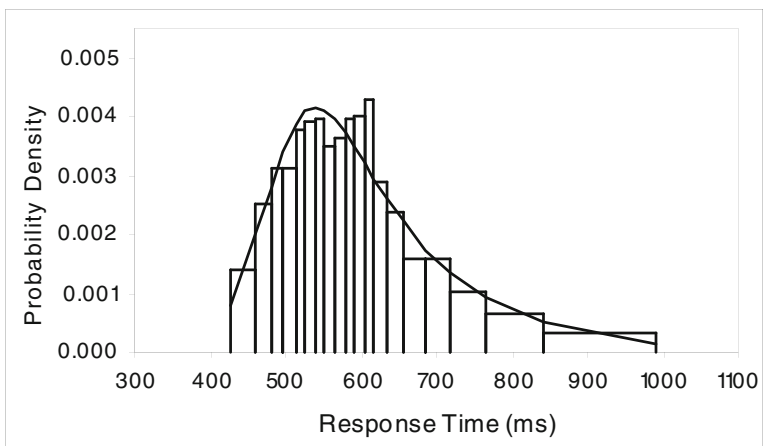

\section{Invalid Cue}

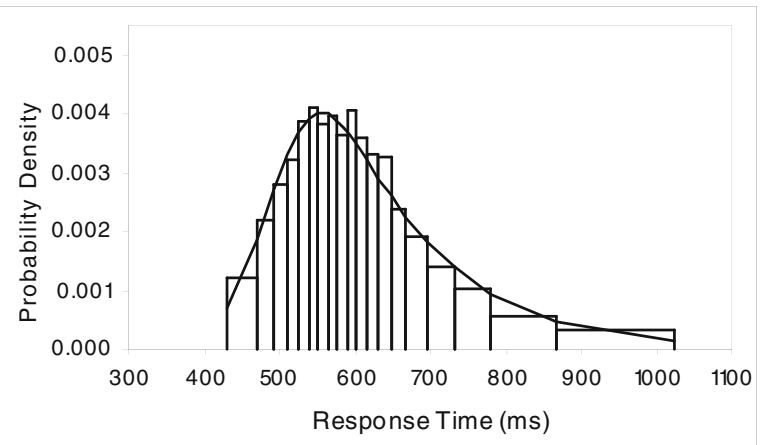

Fig. 8 Fits of the ex-Gaussian function to the data from Experiment 2, as a function of cue type and cue validity 


\section{$\underline{\text { Color Cue }}$}

Valid Cue

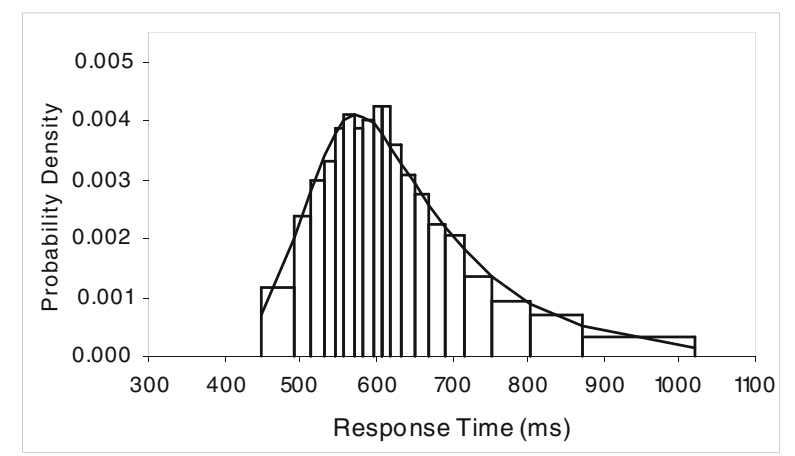

\section{Invalid Cue}

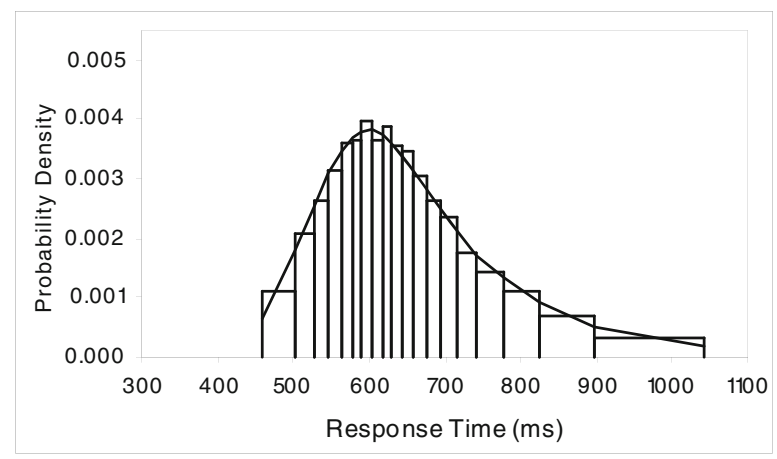

\section{Onset Cue}

\section{Valid Cue}

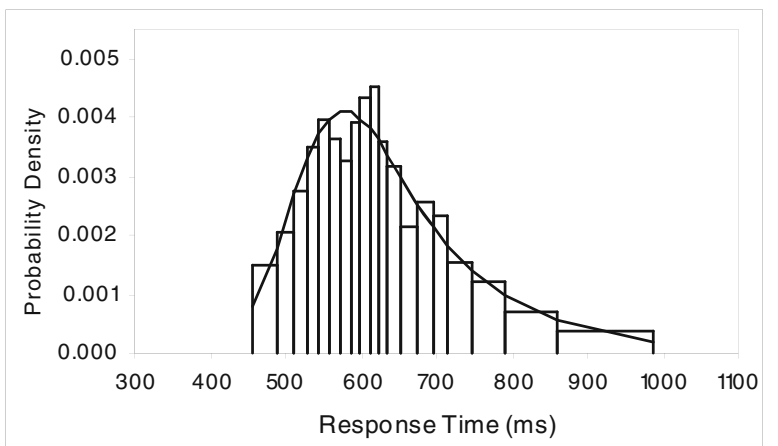

\section{Invalid Cue}

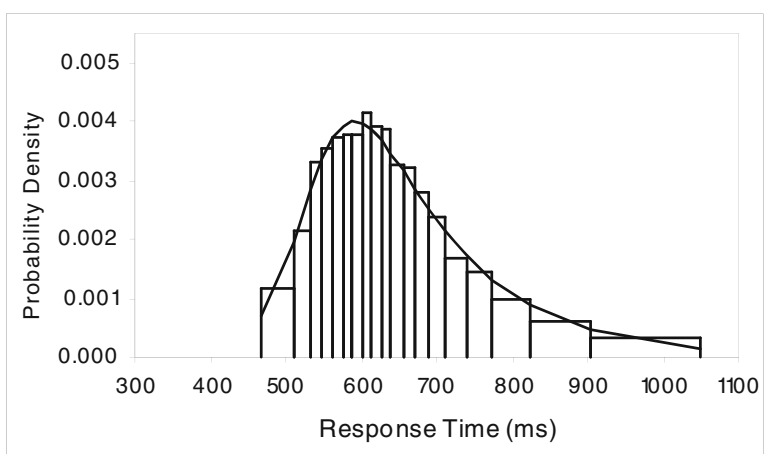

Fig. 9 Fits of the ex-Gaussian function to the data from Experiment 3, as a function of cue type and cue validity

\section{References}

Anderson, B. A., \& Folk, C. L. (2010). Variations in the magnitude of attentional capture: Testing a two-process model. Attention, Perception, \& Psychophysics, 72, 342-352.

Andrews, S., \& Heathcote, A. (2001). Distinguishing common and task-specific processes in word identification: A matter of some moment. Journal of Experimental Psychology: Learning, Memory, and Cognition, 27, 514-544.

Ansorge, U., \& Heumann, M. (2003). Top-down contingencies in peripheral cuing: The roles of color and location. Journal of Experimental Psychology. Human Perception and Performance, 29, 937-948.

Ansorge, U., \& Horstmann, G. (2007). Preemptive control of attentional capture by colour: Evidence from trial-by-trial analyses and orderings of onsets of capture effects in reaction time distributions. The Quarterly Journal of Experimental Psychology, 60, 952-975.

Ansorge, U., Horstmann, G., \& Carbone, E. (2005). Top-down contingent capture by color: Evidence from RT distribution analyses in a manual choice reaction task. Acta Psychologica, 120, 243-266.

Bacon, W. F., \& Egeth, H. E. (1994). Overriding stimulus-driven attention capture. Perception \& Psychophysics, 55, 485- 496.

Balota, D. A., \& Spieler, D. H. (1999). Word frequency, repetition, and lexicality effects in word recognition tasks: Beyond measures of central tendency. Journal of Experimental Psychology. General, 128, 32-55.

Balota, D. A., \& Yap, M. J. (2011). Moving beyond the mean in studies of mental chronometry: The power of response time distribution analyses. Current Directions in Psychological Science, 20, 160-166.

Balota, D. A., Yap, M. J., Cortese, M. J., \& Watson, J. M. (2008). Beyond mean response latency: Response time distribution analyses of semantic priming. Journal of Memory and Language, 59, 495-523.

Belopolsky, A. V., Schreij, D., \& Theeuwes, J. (2010). What is topdown about contingent capture? Attention, Perception, \& Psychophysics, 72, 326-341.

Burnham, B. R. (2007). Display wide visual features associated with a search display's appearance can mediate attentional capture. Psychonomic Bulletin and Review, 14, 392-422.

Burnham, B. R., Harris, A. M., \& Suda, M. T. (2011). Relationship between working memory capacity and contingent involuntary orienting. Visual Cognition, 19, 983-1002.

E-Prime (Version 2.0.8.22) [Computer software]. Pittsburgh, PA: Psychology Software Tools.

Folk, C. L., \& Remington, R. W. (1998). Selectivity by irrelevant featural singletons: Evidence for two forms of attentional capture. Journal of Experimental Psychology. Human Perception and Performance, 24, 847-858.

Folk, C. L., \& Remington, R. W. (2006). Top-down modulation of preattentive processing: Testing the recovery account of contingent capture. Visual Cognition, 14, 445-465. 
Folk, C. L., \& Remington, R. W. (2008). Bottom-up priming of topdown attentional control settings. Visual Cognition, 16, 215-231.

Folk, C. L., Remington, R. W., \& Johnston, J. C. (1992). Involuntary covert orienting is contingent on attentional control settings. Journal of Experimental Psychology. Human Perception and Performance, 18, 1030-1044.

Folk, C. L., Remington, R. W., \& Wright, J. H. (1994). The structure of attentional control: Contingent attentional capture by apparent motion, abrupt onset, and color. Journal of Experimental Psychology. Human Perception and Performance, 20, 317-329.

Gibson, B. S., \& Kelsey, E. M. (1998). Stimulus-driven attentional capture is contingent on attentional set for displaywide visual features. Journal of Experimental Psychology. Human Perception and Performance, 24, 699-706.

Heathcote, A. (1996). RTSYS: A DOS application for the analysis of reaction time data. Behavior Research Methods, Instruments, \& Computers, 28, 427-445.

Heathcote, A., Popiel, S. J., \& Mewhort, D. J. K. (1991). Analysis of response time distributions: An example using the Stroop task. Psychological Bulletin, 109, 340-347.

Hockley, W. E. (1984). Analysis of response time distributions in the study of cognitive processes. Journal of Experimental Psychology: Learning, Memory, and Cognition, 10, 598-615.

Hohle, R. H. (1965). Inferred components of reaction times as functions of foreperiod duration. Journal of Experimental Psychology, 69, 382-386.

Hollands, J. G., \& Jarmasz, J. (2010). Revisiting confidence intervals for repeated measures designs. Psychonomic Bulletin \& Review, 17, $135-138$

Lamy, D., \& Egeth, H. E. (2003). Attentional capture in singletondetection and feature-search modes. Journal of Experimental Psychology. Human Perception and Performance, 29, 10211035.

Lamy, D., Leber, A., \& Egeth, H. E. (2004). Effects of task relevance and stimulus- driven salience in feature-search mode. Journal of Experimental Psychology. Human Perception and Performance, 30, 1019-1031.

Luce, R. D. (1986). Response times: Their role in inferring elementary mental organization. New York: Oxford University Press.

Maljkovic, V., \& Nakayama, K. (1994). Priming of popout: I. Role of features. Memory \& Cognition, 22, 657-672.

Matzke, D., \& Wagenmakers, E.-J. (2009). Psychological interpretation of ex-Gaussian and shifted Wald parameters: A diffusion model analysis. Psychonomic Bulletin \& Review, 16, 798-817.

Mewhort, D. J. K., Braun, J. G., \& Heathcote, A. (1992). Response time distributions and the Stroop task: A Test of the Cohen, Dunbar, and McClelland (1990) model. Journal of Experimental Psychology. Human Perception and Performance, 18, 872-882.

Müller, H. J., Reimann, B., \& Krummenacher, J. (2003). Visual search for singleton feature targets across dimensions: Stimulus and expectancy-driven effects in dimensional weighting. Journal of Experimental Psychology. Human Perception and Performance, 29. 1021-1035. doi:10.1037/0096-1523.29.5.1021

Neely, J. H. (1977). Semantic priming and retrieval from lexical memory: Roles of inhibitionless spreading activation and limited-capacity attention. Journal of Experimental Psychology. General, 106, 226-254.

Pashler, H. (1988). Cross-dimensional interaction and texture segregation. Perception \& Psychophysics, 43, 301-318.
Ratcliff, R. (1978). A theory of memory retrieval. Psychological Review, 85, 59-108.

Ratcliff, R. (1979). Group reaction time distributions and an analysis of distribution statistics. Psychological Review, 86, 446-461.

Ratcliff, R., \& Murdock, B. B., Jr. (1976). Retrieval processes in recognition memory. Psychological Review, 83, 190-214.

Rouder, J. N. (2005). Are unshifted distributional models appropriate for response time? Psychometrika, 70, 377-381.

Rouder, J. N., \& Speckman, P. L. (2004). An evaluation of the vincentizing method for forming group-level response time distributions. Psychonomic Bulletin \& Review, 11, 419-427.

Theeuwes, J. (1992). Perceptual selectivity for colour and form. Perception \& Psychophysics, 51, 599-606.

Theeuwes, J. (1994). Bottom-up capture and attentional set: Selective search for colour and visual abrupt onsets. Journal of Experimental Psychology. Human Perception and Performance, 20, 799806.

Theeuwes, J. (2010). Top-down and bottom-up control of visual selection. Acta Psychologica, 123, 77-99.

Theeuwes, J., Atchley, P., \& Kramer, A. F. (2000). On the time course of top-down and bottom-up control of visual attention. In S. Monsell \& J. Driver (Eds.), Attention and performance XVIII: Control of cognitive performance (pp. 105-125). Cambridge, MA: MIT Press.

Theeuwes, J., \& Godijn, R. (2002). Irrelevant singletons capture attention: Evidence from inhibition of return. Perception \& Psychophysics, 64, 764-770.

Tse, C.-S., Hutchison, K. A., \& Li, Y. (2011). Effects of contextual similarity and target-repetition proportion on negative priming in RT distribution analyses. Journal of Experimental Psychology. Human Perception and Performance, 37, 180-192.

Van Zandt, T. (2000). How to fit a response time distribution. Psychonomic Bulletin \& Review, 19, 424-465.

Wenger, M. J., \& Gibson, B. S. (2004). Using hazard functions to assess changes in processing capacity in an attentional cuing paradigm. Journal of Experimental Psychology. Human Perception and Performance, 30, 708-719.

Wei, P., Lü, J., Müller, H. J., \& Zhou, X. (2008). Searching for two feature singletons in the visual scene: The localized attentional interference. Experimental Brain Research, 185, 175-188. doi:10.1007/s00221007-1141-7

Worschech, F., \& Ansorge, U. (2012). Top-down search for color prevents voluntary directing of attention to informative singleton cues. Experimental Psychology, 59, 153-162.

Yantis, S. (1993). Stimulus-driven attentional capture and attentional control settings. Journal of Experimental Psychology. Human Perception and Performance, 19, 676-681.

Yantis, S. (2000). Goal-directed and stimulus-driven determinants of attentional capture (tutorial). In S. Monsell \& J. Driver (Eds.), Control of cognitive processes: Attention and performance XVIII (pp. 73-103). Cambridge, MA: MIT Press.

Yantis, S., \& Egeth, H. E. (1999). On the distinction between visual salience and stimulus-driven attentional capture. Journal of Experimental Psychology. Human Perception and Performance, 25, 661-676.

Yap, M. J., Balota, D. A., Cortese, M. J., \& Watson, J. M. (2006). Single- versus dual-process models of lexical decision performance: Insights from response time distribution analysis. Journal of Experimental Psychology. Human Perception and Performance, 32, 1324-1344. 